\title{
Zymomonas diversity and potential for biofuel production
}

\author{
Magdalena M. Felczak ${ }^{1}$, Robert M. Bowers ${ }^{2}$ (D) Tanja Woyke ${ }^{2}$ (D) and Michaela A. TerAvest ${ }^{1 *}$ (D)
}

\begin{abstract}
Background: Zymomonas mobilis is an aerotolerant a-proteobacterium, which has been genetically engineered for industrial purposes for decades. However, a comprehensive comparison of existing strains on the genomic level in conjunction with phenotype analysis has yet to be carried out. We here performed whole-genome comparison of 17 strains including nine that were sequenced in this study. We then compared 15 available Zymomonas strains for their natural abilities to perform under conditions relevant to biofuel synthesis. We tested their growth in anaerobic rich media, as well as growth, ethanol production and xylose utilization in lignocellulosic hydrolysate. We additionally compared their tolerance to isobutanol, flocculation characteristics, and ability to uptake foreign DNA by electroporation and conjugation.

Results: Using clustering based on 99\% average nucleotide identity (ANI), we classified 12 strains into four clusters based on sequence similarity, while five strains did not cluster with any other strain. Strains belonging to the same 99\% ANI cluster showed similar performance while significant variation was observed between the clusters. Overall, conjugation and electroporation efficiencies were poor across all strains, which was consistent with our finding of coding potential for several DNA defense mechanisms, such as CRISPR and restriction-modification systems, across all genomes. We found that strain ATCC31821 (ZM4) had a more diverse plasmid profile than other strains, possibly leading to the unique phenotypes observed for this strain. ZM4 also showed the highest growth of any strain in both laboratory media and lignocellulosic hydrolysate and was among the top 3 strains for isobutanol tolerance and electroporation and conjugation efficiency.

Conclusions: Our findings suggest that strain ZM4 has a unique combination of genetic and phenotypic traits that are beneficial for biofuel production and propose investing future efforts in further engineering of ZM 4 for industrial purposes rather than exploring new Zymomonas isolates.
\end{abstract}

\section{Background}

Zymomonas mobilis is becoming a popular bacterial host for biofuel research due to its fast growth, tolerance of ethanol and toxins found in lignocellulosic hydrolysates (lignotoxins), and high specificity of ethanol production [1]. However, there are also key challenges for working with Z. mobilis that differ significantly from working

\footnotetext{
*Correspondence: teraves2@msu.edu

1 Department of Biochemistry and Molecular Biology, Michigan State University, East Lansing, Ml 48824, USA

Full list of author information is available at the end of the article
}

with other biofuel producers, such as yeast. Specifically, its use of the Entner-Doudoroff glycolytic pathway is poorly understood, it lacks a well-developed genetic toolbox, and it does not have a long history of industrial use [1]. As a result of these challenges, it has been difficult to convert $Z$. mobilis from an efficient ethanologen into an advanced biofuel platform. Moving forward, biofuel production efforts must focus on advanced fuels and improve microbe capabilities to use the wide range of substrates available in lignocellulosic hydrolysates. Significant investment is thus necessary to build the tools and

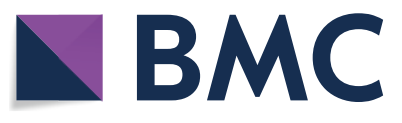

c) The Author(s) 2021. This article is licensed under a Creative Commons Attribution 4.0 International License, which permits use, sharing, adaptation, distribution and reproduction in any medium or format, as long as you give appropriate credit to the original author(s) and the source, provide a link to the Creative Commons licence, and indicate if changes were made. The images or other third party material in this article are included in the article's Creative Commons licence, unless indicated otherwise in a credit line to the material. If material is not included in the article's Creative Commons licence and your intended use is not permitted by statutory regulation or exceeds the permitted use, you will need to obtain permission directly from the copyright holder. To view a copy of this licence, visit http://creativeco mmons.org/licenses/by/4.0/. The Creative Commons Public Domain Dedication waiver (http://creativecommons.org/publicdomain/ zero/1.0/) applies to the data made available in this article, unless otherwise stated in a credit line to the data. 
knowledge required to enable rapid and effective engineering of $Z$. mobilis for these features.

One approach to improve biofuel-producing organisms is to take advantage of naturally occurring genetic diversity within a species or genus, as has been successful in yeast [2]. Comparative genomics is now starting to be utilized in Zymomonas and several Z. mobilis genomes were compared in a recent analysis [3]. This comparison showed a high degree of similarity between Zymomonas genomes, although different strains had different plasmid sets. This is in line with an earlier phenotypic characterization which showed relatively low diversity, and only one species (mobilis) within the genus Zymomonas [4]. However, the previous studies did not combine genome sequence analysis with phenotypic analysis, therefore, it is difficult to make inferences about gene function from their datasets. We hypothesized that by expanding the set of available genomes in conjunction with performing physiological characterization of all accessible strains, new connections between specific genes, operons, and/ or plasmids and phenotypic biofuel-relevant traits could be revealed.

To better understand Z. mobilis as a platform organism, we combined a comparative genomics approach with physiological characterization. Specifically, we compared the genomes of 17 strains, including 8 which had previously been sequenced $[3,5-11]$ and 9 which were sequenced at the Joint Genome Institute for this study
(Table 1). Specific sequencing information, such as read coverage for each genome sequenced in this study is in Additional file 1: Table S1. Here, strains are defined as separate isolates or derivates that have been deposited to strain collections under unique identifiers. The strains were originally isolated from several locations around the world, across North and South America, Africa, and Europe (Additional file 1: Table S2). The strains were primarily obtained from fermentations intended to produce alcohol for human consumption. One strain (PROIMI A1) was isolated specifically for research purposes [12]. In some cases, the Zymomonas was a normal component of the fermentation and in other cases (European isolates) it was considered a contaminant [13]. While Zymomonas strains have previously been found in environmental samples, including bees, we were not able to obtain any such isolates [14]. Future studies may be able to expand knowledge of the Zymomonas genus by focusing on strains not isolated from human-associated fermentations. We compared the strains for their growth rates in rich media, tolerance of lignocellulosic hydrolysate and isobutanol, conjugation and transformation efficiencies, and flocculation characteristics.

We obtained and physiologically characterized as many of the Zymomonas strains as possible using three publicly available culture collections; the American Type Culture Collection (ATCC), the German Collection of Microorganisms and Cell Cultures (DSMZ), and the

Table 1 Information on Zymomonas genomes

\begin{tabular}{|c|c|c|c|c|c|c|c|c|}
\hline Common & IMG.taxID & NCBI accession \# & SRA accession \# & $\begin{array}{l}\text { Gene } \\
\text { count }\end{array}$ & $\begin{array}{l}\text { Scaffold } \\
\text { count }\end{array}$ & $\begin{array}{l}\text { hierBAPS } \\
\text { cluster }\end{array}$ & $\begin{array}{l}\text { ANI_99 } \\
\text { cluster }\end{array}$ & Genome reference \\
\hline ZM4 & 2834884446 & NZ_CP023715 & & 2008 & 5 & 1 & 7 & [5] \\
\hline B-1960 & 2834983939 & NZ_CP021053 & & 1837 & 1 & 1 & 4: CP1 & {$[6]$} \\
\hline CP1 & 2811994965 & NZ_VIVG01000001.1 & SRP196443 & 1823 & 4 & 1 & 4: CP1 & This study \\
\hline CP3 & 2818991419 & NZ_VIVT01000001.1 & SRP196448 & 1670 & 22 & 1 & 2: CP4 & This study \\
\hline CP4 & 2545555880 & NC_022900 & & 1933 & 6 & 1 & 2: CP4 & {$[7]$} \\
\hline B-12526 & 2558860209 & NZ_CP003709 & & 1916 & 6 & 1 & 2: CP4 & [3] \\
\hline Z6 & 2634166410 & NC_018145 & & 1847 & 4 & 4 & 3: Z6 & [8] \\
\hline B-23394 & 2811994876 & NZ_VFNW01000001.1 & SRP196447 & 1869 & 4 & 4 & $3: Z 6$ & This study \\
\hline B-4492 & 2811994895 & NZ_VFOD01000001.1 & SRP196445 & 1873 & 5 & 4 & 3:Z6 & This study \\
\hline ATCC 10988 & 645058785 & NZ_ACQU01000001 & & 1894 & 24 & 2 & 1: Drainas & {$[9]$} \\
\hline CU1 & 2811994958 & NZ_VFOH01000001.1 & SRP196503 & 1880 & 3 & 2 & 1: Drainas & This study \\
\hline CU1rif2 & 2811994957 & NZ_VIVF01000001.1 & SRP196507 & 1896 & 4 & 2 & 1: Drainas & This study \\
\hline uvs51 & 2811994963 & NZ_VFOI01000001.1 & SRP196501 & 1903 & 5 & 2 & 1: Drainas & This study \\
\hline PROIMI A1 & 2811994956 & NZ_VFOG01000001.1 & SRP196506 & 1877 & 4 & 1 & 6 & This study \\
\hline NCIMB11163 & 646311969 & NC_013355 & & 1978 & 4 & 1 & 8 & {$[10]$} \\
\hline francensis & 2811994955 & NZ_VFOF01000001.1 & SRP196505 & 1882 & 7 & 3 & 5 & This study \\
\hline pomaceae & 650716107 & NC_015709 & & 1838 & 3 & 3 & 9 & {$[11]$} \\
\hline
\end{tabular}

Common strain names were used in the table and in the text. Other names used by different strain collections are listed in Additional file 1: Table S2 for crossreference. For strains with multiple scaffolds, NCBI Acc \# for the largest contig is shown; smaller contigs have consecutive numbers. Contigs recognized as plasmids are listed in Additional file 1: Table S3 with specific accession numbers. SRA accession numbers are provided for the genomes sequenced for this study 
USDA Agricultural Research Service Culture Collection (NRRL). Two strains, NCIMB11163 and B-12526, were not readily available from culture collections, resulting in a total of 15 strains for phenotyping.

\section{Results and discussion}

\section{Phylogenetic analysis}

We explored the phylogenetic relationships of all 17 Zymomonas strains by first constructing a concatenated marker gene tree using a set of 56 universal single copy markers [15]. Based on this tree, most Zymomonas isolates were highly similar, with a slight branching of the pomaceae and francensis subspecies in the marker gene tree (Fig. 1a). To increase resolution, a single nucleotide polymorphism (SNP) tree was constructed, which showed increased branching patterns between the genomes [16]. We analyzed the branching pattern together with two separate clustering approaches, hierarchical Bayesian clustering (hierBAPS) [17, 18] and 99\% average nucleotide identity (ANI) clustering (Fig. 1b, c). The hierBAPS approach placed the isolates into 4 distinct genome clusters, while 9 clusters resulted from the 99\% ANI clustering. Based on 99\% ANI clustering, most of the 17 sequenced Zymomonas strains can be classified into four multi-strain clusters, which we refer to as CP1 (ANI_99 cluster 4), CP4 (ANI_99 cluster 2), Z6 (ANI_99 cluster 3), and Drainas (ANI_99 cluster 1) (Table 1; Fig. 1). Each group was named for the most commonly studied strain within the group, except for the Drainas group, which was named for the research group that generated three of the four strains. Five strains did not cluster with any other strains based on 99\% ANI, including $Z$. mobilis subsp. pomaceae, Z. mobilis subsp. francensis, PROIMI A1, NCIMB11163, and ZM4. Throughout this work, we use ZM4 as the comparator strain, and group PROIMI A1, francensis, pomaceae and NCIMB11163 together in a 'none' group. In general, the clusters align with our expectations based on the history of each strain as described below.

The CP1 group consists of two strains, CP1 and B-1960. Strain CP1 was isolated from fermenting sugarcane juice in Recife, Brazil [19] and strain B-1960 was isolated from spoiled beer by H.J. Bunker of Barclay Perkins \& Co., Ltd (Table 1). The CP4 group includes two strains that were isolated from the same market as CP1 (CP3 and CP4), and a flocculating variant of $\mathrm{CP} 4$ developed at Oak Ridge National Lab, B-12526 [20]. Three additional strains fall within this large branch but do not fall within one of the clustering groups, PROIMI A1, NCIMB11163, and ZM4. Strain PROIMI A1 was isolated in Argentina from fermenting sugarcane juice. PROIMI A1 has not been widely studied, but previous work shows that it flocculates readily and has plasmids that can be repurposed for genetic modification purposes [12]. NCIMB11163 was isolated from ale in England in the 1970s [21]. The origin of strain ZM4 is somewhat unclear, because it is either a derivative or contaminant of $\mathrm{CP} 4$. After several decades of research on $\mathrm{CP} 4$, research groups realized that not

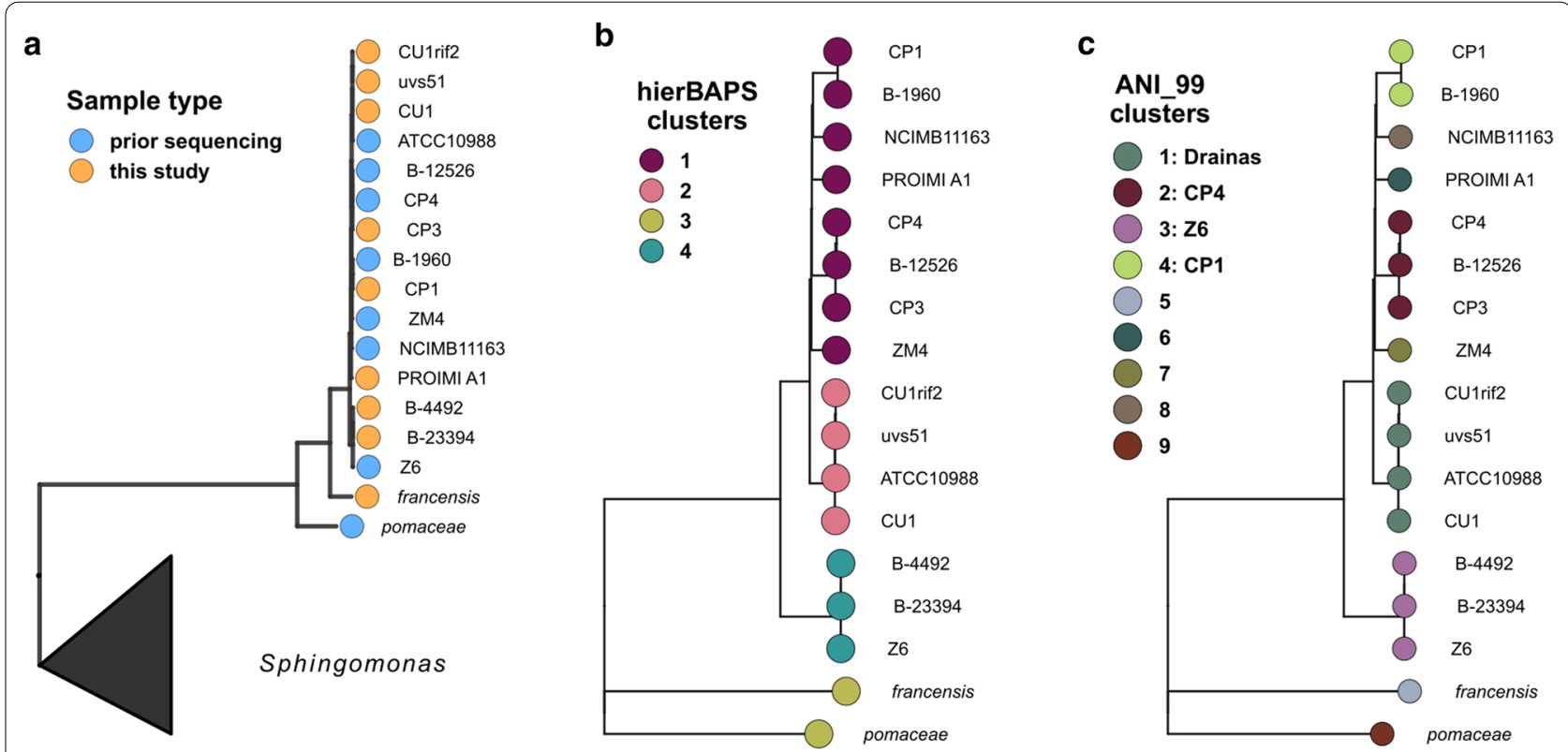

Fig. 1 Strain-level resolution across 17 Zymomonas genomes. a Whole genome trees based on the alignment and concatenation of 56 universal marker genes. b, c SNP trees of the same 17 Zymomonas where genomes are colored by either a hierarchical Bayesian clustering of the whole-genome alignment (b) or by the groups identified as a result of $99 \%$ ANI clusering (alignment fraction greater than $70 \%$ ) 
all strains designated CP4 were identical and designated ZM4 as a separate group because of differing plasmid profiles [22]. Despite the history of the two strains, there are significant differences in their genome sequences [7]. In our analysis, ZM4 did not cluster with either the CP1 or $\mathrm{CP} 4$ groups, despite the expectation that they would be close relatives based on strain history.

The Z6 group is formed by three strains; two that were isolated from fermenting palm sap in Zaire (Z6 and B-23394), and a third, B-4492, which is listed in the NRRL catalog as identical to strain B-1960 (from the CP1 group) [23]. We observed that strain B-4492 is phenotypically and genetically much more similar to the strains originating in Zaire than to the CP1 group. We suggest that strain B-4492 is likely an isolate from Zaire and therefore include it with the Z6 group.

The Drainas group is formed by the type strain, ATCC10988, and three derivative strains created by mutagenesis and selection by Dr. Constantin Drainas and coauthors. ATCC10988 was isolated from fermenting agave sap in Mexico in 1924 [4]. Strain CU1 was developed by incubating ATCC10988 with acridine orange and was reported to have a decreased tolerance to glucose concentrations $\geq 20 \%$ [24]. Strain CU1rif2 is a derivative of CU1 developed by further treatment with acridine orange and screening for rifampicin resistance [25]. Strain uvs51 is a derivative of CU1rif2 and was developed by mutagenizing with MNNG and screening for UV sensitivity [26]. Based on the relationships between these strains, we expect all three derivative strains to be sensitive to high glucose concentrations and CU1rif2 and uvs51 to be resitant to rifampicin. All strains showed the expected phenotypes (Additional file 1: Figure S1).
Z. mobilis subsp. pomaceae and Z. mobilis subsp. francensis were the most genetically distinct from the rest of the Zymomonas strains. Z. mobilis subsp. francensis strains were isolated from contaminated cider in France in 2001 [27]. These strains were designated as a separate subspecies based on differences in proteome (as observed by SDS-PAGE) and differences from subsp. mobilis and subsp. pomaceae in sucrose fermentation and tolerance of bile salts. Similarly, Z. mobilis subsp. pomaceae strains were isolated from contaminated cider in England [13].

\section{Zymomonas mobilis pangenome}

The pangenome of the Zymomonas strains was assessed by assigning genes to ortholog clusters and generating a rarefaction curve by plotting the number of unique orthologue groups as a function of total gene content, with a step size of 100 genes (Fig. 2a). A Venn diagram was also generated to visualize the number of ortholog clusters shared or unique among the four hierBAPS clusters (Fig. 2b). There were 2,564 unique gene families and while the rarefaction curve appears to approach an asymptote, the number of unique gene families is still increasing, suggesting that there are more unique gene families to be discovered when increasing the number of sampled genomes, i.e., the pangenome may be open. The Venn diagram does display however, that most unique gene families are observed in the core $(62 \%$, dark blue), suggesting that while we do not yet have a closed pangenome, these Zymomonas genomes have a relatively small accessory component.
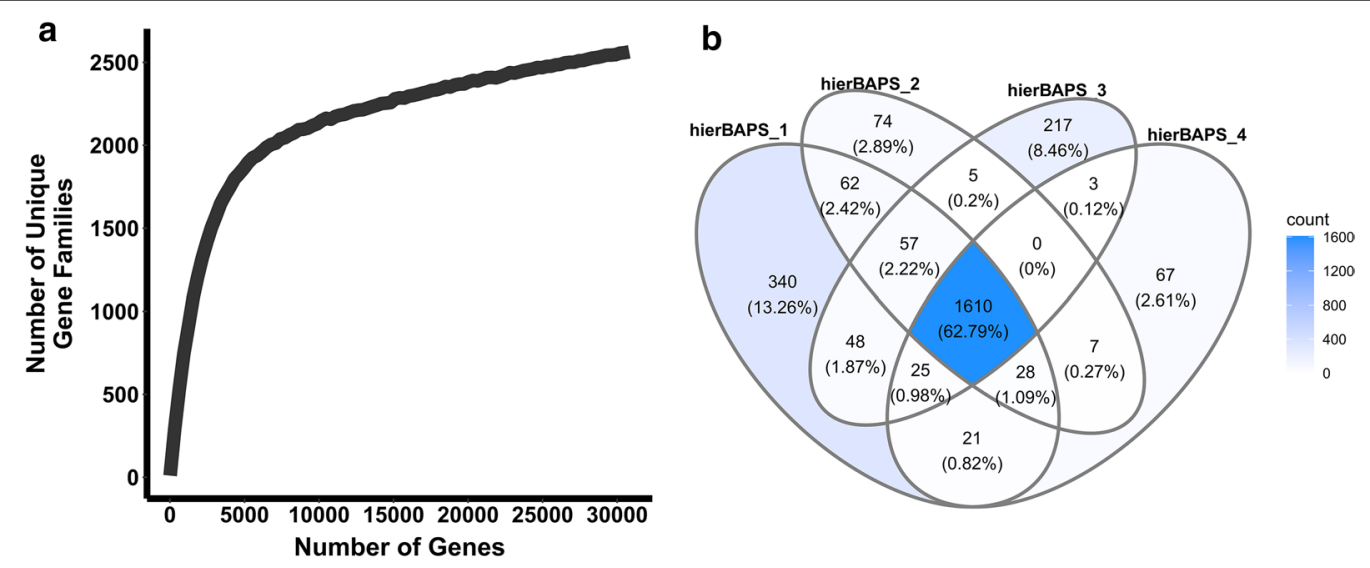

Fig. 2 Pangenome of 17 Zymomonas genomes as determined based on the number of unique gene families/orthologues observed in each genome. a Rarefaction curve of the number of unique gene families compared to the total sampled. $\mathbf{b}$ Venn diagram grouped into 4 ellipses where each ellipse corresponds to a dereplicated set of orthologue ids (a.k.a. genes) from genome sets corresponding to the hierBAPs SNP genome clusters 


\section{Zymomonas mobilis plasmids}

Beyond chromosome sequences, PacBio sequencing revealed multiple circular plasmids in 6 of 9 genomes analyzed. In two strains (CP1 and CU1), only small linear contigs were found, which may represent incompletely sequenced or linear plasmids. CP3 was assembled in 22 linear contigs, some of which may represent plasmids. The new and previously identified plasmids and linear contigs are summarized in Table 2 and accession numbers for all contigs and topology determination are included in Additional file 1: Table S3. Each group of strains appears to have a common set of plasmids, which share over $99.97 \%$ ANI. There is little homology between plasmids from different groups. Interestingly, three out of four plasmids of ZM4 share partial homolgy with plasmids from two other groups: CP4 and Drainas. Namely, $64 \%$ of p32.8 has $96 \%$ ANI to p32.3 of ATCC10988 and 78 and $61 \%$ of p36.5 and p39.3 share 98\% ANI with p36.9 and p32.4 of the CP4 group, respectively. It is possible that ZM4 evolved from CP4 but developed a unique set of plasmids through conjugation with other Zymomonas strains during serial passage in the laboratory, which would explain its unusual history.

One of the most important features found on extrachromosomal elements is the Type I restriction-modification ( $\mathrm{R}-\mathrm{M}$ ) system, encoded by $h s d R M S$ genes. At least one such system was found on plasmids in all four groups and in ZM4 and pomaceae (highlighted in Table 2). Consistent with the ANI between the plasmids, BLASTp confirmed almost $100 \%$ amino acid identity between the R-M subunits (Restriction, Methylation, and Specificity) within the same group. Interestingly, although $R$ and $M$ subunits encoded on p32.8 of ZM4 show 99\% amino acid identity to respective proteins encoded on p32.3 of ATCC10988, the putative S subunit is annotated as a hypothetical protein and has only $39 \%$ homology to respective subunit of ATCC10988. Similarly, although $\mathrm{R}$ and $\mathrm{M}$ subunits of the $\mathrm{R}-\mathrm{M}$ system in pomaceae show $95 \%$ amino acid identity to subunits on CP4's p30.9, the S subunit has only $38 \%$ identity to the same subunit of CP4. Hence, the specificity factor of Type I R-M system seems to evolve faster than endonuclease and methylase, possibly as a result of adaptation to new foreign DNA sequences present in a changing environment. Except for those in ZM4 and pomaceae, no hsdRMS genes were found on plasmids present in strains outside of the four groups. It is noteworthy that ZM4 was the only strain with $h s d M S$ genes found on the chromosome without a corresponding $h s d R$ identified.

Table 2 Summary of Zymomonas mobilis plasmids and their Type I R-M systems (hsdRMS systems)

\begin{tabular}{|c|c|c|c|}
\hline Group & Strain & Plasmids (kb) & Linear contigs (kb) \\
\hline \multirow[t]{2}{*}{ CP1 } & B-1960 & 1.7 & \\
\hline & $\mathrm{CP} 1$ & ND & $1,6.7,6.5$ \\
\hline \multirow{3}{*}{ CP4 } & CP3 & ND & $N^{2}$ \\
\hline & CP4 & $36.9,33.9,32.4,30.9,30.4$ & -- \\
\hline & B-12526 & $37.1,33.9,32.4,30.9,32.8$ & -- \\
\hline & Z6 & $13.7,14.9,18.3$ & -- \\
\hline \multirow[t]{2}{*}{$\mathbf{Z 6}$} & B-23394 & $13.7,14.9,33.5$ & -- \\
\hline & B-4492 & $13.7,14.9,33.5$ & -- \\
\hline \multirow[t]{9}{*}{ Drainas } & ATCC10988 & $32.5,32.3,31.7,18.5,4.0,2.7$ & -- \\
\hline & CU1 & ND & $24.7,25.1^{3}$ \\
\hline & CU1rif2 & $33.3,32.3,31.7$ & -- \\
\hline & uvs51 & $32.4,32.3,31.7$ & -- \\
\hline & ZM4 & $36.5,32.8,39.3,33.0$ & -- \\
\hline & PROIMIA1 & $35.9,20.5,29.0$ & -- \\
\hline & $\begin{array}{l}\text { NCIMB } \\
11163\end{array}$ & $53.4,4.5, \quad 40.8$ & -- \\
\hline & francensis & $28.4,27.6,31.9,15.4$ & $13.7,4.5$ \\
\hline & pomaceae & $37.4,34.2$ & -- \\
\hline
\end{tabular}

Plasmids are named by size as determined in NCBI nucleotide database. Full names and NCBI accession numbers of all plasmids are listed in Additional file 1: Table S3. BLASTn of whole plasmids sequences was used to determine their ANI. Plasmids shared by more than one strain in the group were assigned the same colors, i.e., all blue-labeled plasmid were shared by multiple strains in the CP4 group. Homologous plasmids ( $>99 \%$ ANI) are vertically aligned, i.e., the blue-labeled plasmids in the ZM4 row are homologous to the corresponding blue-labeled plasmids in the CP4 row. Plasmids with no significant homology to other plasmids are shown in black. Plasmids with annotated $h s d R M S$ genes are highlighted (see details in text). ND-not detected

${ }^{1} h s d M S$ and truncated $h s d R$ with $100 \%$ aa identity to $h s d R M S$ on linear contig 34.5 of B-1960

${ }^{2}$ The CP3 chromosome could not be assembled into a circular contig; the genome could only be assembled into 22 linear contigs. Therefore, we could not distinguish between putative chromosomal and plasmid contigs.

${ }^{3} 99 \%$ nucleotide identity to 32.3 of ATCC10988 but no hsdRMS genes 


\section{Comparison of growth in rich medium}

We compared growth of all strains in rich medium in anoxic conditions to determine growth rates (Fig. 3). Grouping the growth curves based on the phylogenetic tree reveals similarities within the groups. ZM4 and strains in the Z6 group have the fastest growth rates. Strains in the CP1 and CP4 groups grew more slowly than ZM4 and Z6. The type strain and its derivatives in the Drainas group show that two of the mutants have a growth defect compared with the parent strain. Of the strains that could not be classified, the francensis subspecies grew more slowly than all other strains. The pomaceae subspecies also grew slowly.

The exponential growth rates and doubling times for the growth curves were calculated by fitting logistic curves to the data in Fig. 3 and are reported in Table 3. Strains in the Z6 group along with ZM4 and CP4 showed the highest growth rates and shortest doubling times. Flocculation of some strains (Fig. 3b) caused instability in the apparent growth rates, making the doubling time an unreliable summary statistic for some of these growth curves. Therefore, we also report the area under the curve after $20 \mathrm{~h}\left(\mathrm{AUC}_{20}\right)$ as a summary of growth, which takes into account both the growth rate and the final density [28]. ZM4 and Z6 group strains showed the highest growth as measured by $\mathrm{AUC}_{20}$, the $\mathrm{CP} 1, \mathrm{CP} 4$ and Drainas groups showed intermediate growth, and the unclassified strains showed variable growth with francensis showing the lowest growth (Table 3).

\section{Comparison of growth in lignocellulosic hydrolysate}

Because of significant costs associated with purifying sugars from lignocellulosic materials, ideal biofuel-producing strains should have the capability to grow directly
Table 3 Growth statistics for Zymomonas strains calculated from data in Fig. 3

\begin{tabular}{llllc}
\hline Group & Strain & $\mathbf{r}\left(\mathbf{h}^{-\mathbf{1}}\right)$ & $\begin{array}{l}\text { Doubling time } \\
(\mathbf{h})\end{array}$ & $\mathbf{A U C}_{\mathbf{2 0}}$ \\
\hline CP1 & B-1960 & $0.53 \pm 0.03$ & $1.30 \pm 0.07$ & $16.55 \pm 0.93$ \\
& CP1 & $0.58 \pm 0.02$ & $1.19 \pm 0.04$ & $16.52 \pm 1.00$ \\
& CP3 & $0.55 \pm 0.02$ & $1.27 \pm 0.06$ & $12.00 \pm 0.43$ \\
CP4 & CP4 & $0.79 \pm 0.06$ & $0.88 \pm 0.06$ & $16.20 \pm 0.39$ \\
& Z6 & $0.74 \pm 0.04$ & $0.95 \pm 0.06$ & $17.5 \pm 0.40$ \\
Z6 & B-23394 & $0.71 \pm 0.03$ & $0.98 \pm 0.04$ & $17.40 \pm 0.15$ \\
& B-4492 & $0.79 \pm 0.09$ & $0.89 \pm 0.09$ & $17.62 \pm 0.35$ \\
Drainas & ATCC10988 & $0.64 \pm 0.02$ & $1.09 \pm 0.02$ & $13.25 \pm 0.50$ \\
& CU1 & $0.53 \pm 0.02$ & $1.32 \pm 0.04$ & $13.2 \pm 0.35$ \\
& CU1 rif2 & $0.40 \pm 0.01$ & $1.75 \pm 0.06$ & $9.43 \pm 0.13$ \\
& uv551 & $0.39 \pm 0.03$ & $1.78 \pm 0.12$ & $9.68 \pm 0.12$ \\
& ZM4 & $0.67 \pm 0.01$ & $1.03 \pm 0.01$ & $17.59 \pm 0.25$ \\
& PROIMIA1 & $0.58 \pm 0.01$ & $1.20 \pm 0.03$ & $14.43 \pm 0.23$ \\
& francensis & $0.47 \pm 0.02$ & $1.46 \pm 0.05$ & $9.97 \pm 0.68$ \\
& pomaceae & $0.50 \pm 0.02$ & $1.38 \pm 0.04$ & $10.80 \pm 0.26$ \\
\hline
\end{tabular}

Logistic curves were fit to the measured growth curves using the $R$ package 'growthcurver'. The calculated exponential growth rate (r), doubling time, and area under the curve after $20 \mathrm{~h}\left(\mathrm{AUC}_{20}\right)$ are reported as average \pm standard error $(\mathrm{N}=3)$

in lignocellulosic hydrolysates. However, these hydrolysates can be stressful environments for microbes, due to high sugar concentrations, lignotoxins such as furfural or phenolic aldehydes, and low $\mathrm{pH}$ due to organic acids [29-31]. Therefore, we measured how well each Zymomonas strain tolerated lignocellulosic hydrolysate during anaerobic growth. All strains except the francensis subspecies were able to grow in lignocellulosic hydrolysate, although some required a relatively dense
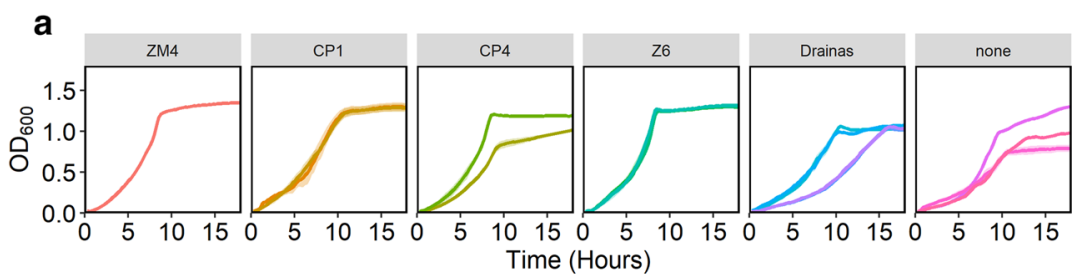

b

(-) ZM4
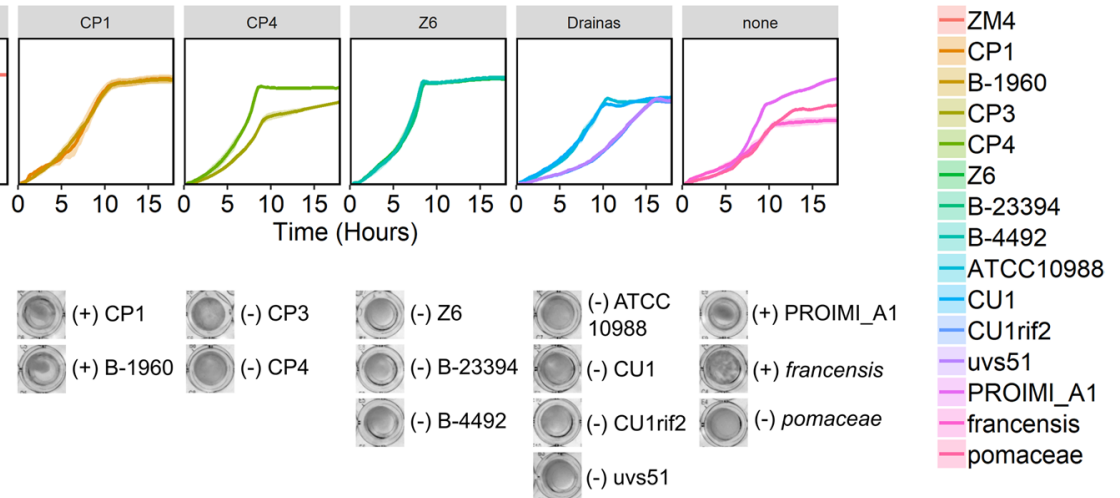

Fig. 3 Growth curves of Zymomonas strains. Strains were grown in rich medium in 96-well plates with shaking, in anoxic conditions. Represented by $\mathbf{a} \mathrm{OD}_{600}$ versus time and $\mathbf{b}$ representative images of wells after $45 \mathrm{~h}$ of growth showing varying levels of flocculation with a $(+)$ or $(-)$ indicating whether flocs were present or absent based on visual inspection. In A, lines represent the average of three biological replicates and ribbons represent standard error 
inoculum (initial $\mathrm{OD}_{600}=0.5$ ) to enable growth and ethanol production (Figs. 4 and 5). The requirement of some strains for a dense inoculum to grow may reflect higher

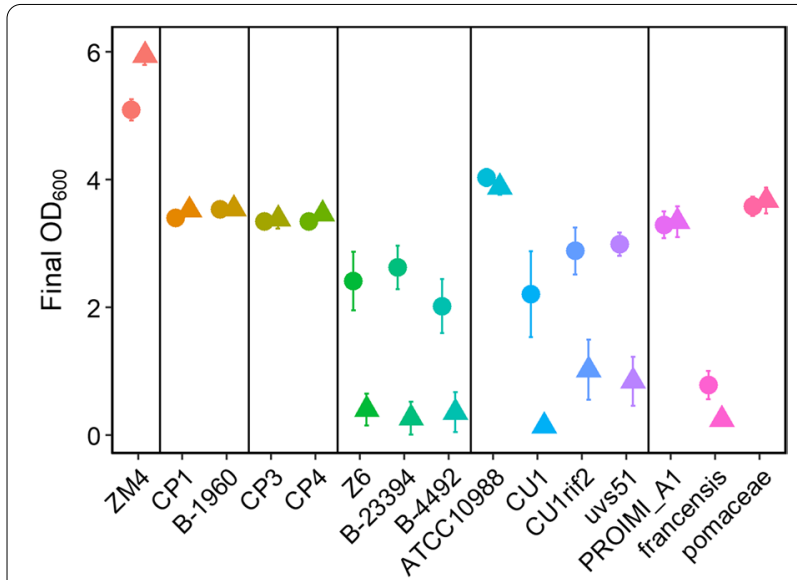

Fig. 4 Growth of Zymomonas strains in lignocellulosic hydrolysate. The final $\mathrm{OD}_{600}$ after $55 \mathrm{~h}$ of growth is shown. Cultures were inoculated to a starting $\mathrm{OD}_{600}$ of 0.1 (triangles) or 0.5 (circles). Points represent the average of three biological replicates and error bars represent standard error sensitivity of these strains to toxins present in hydrolysate. Previous work with Escherichia coli demonstrated that increased inoculation density improved growth in the presence of furfural and phenolic aldehydes [32]. Strain ZM4 grew to a higher final $\mathrm{OD}_{600}$ than any of the other strains.

The Drainas group provides interesting comparisons to examine genes relevant to hydrolysate tolerance because of the variation in hydrolysate tolerance despite very similar genomes. Within the Drainas group, the derivatives of ATCC10988 did not grow well in hydrolysate and required a high inoculum, unlike their parent strain. CU1 and CU1rif2 could not consume all glucose in the hydrolysate even at the higher inoculum level. These strains' previously documented intolerance of high glucose concentrations may explain the poor growth of the mutant strains on hydrolysate (6\% glucose in the hydrolysate used here). Genome comparison between the four strains reveals that all three derivatives lost a set of 41 genes present in the parent strain (Additional file 1: Table S4). Of these, 37 were annotated as hypothetical proteins, 3 had general protein family annotations and one was annotated as a ribosomal protein. It seems likely that some of these 41 genes contribute to glucose tolerance, but at the
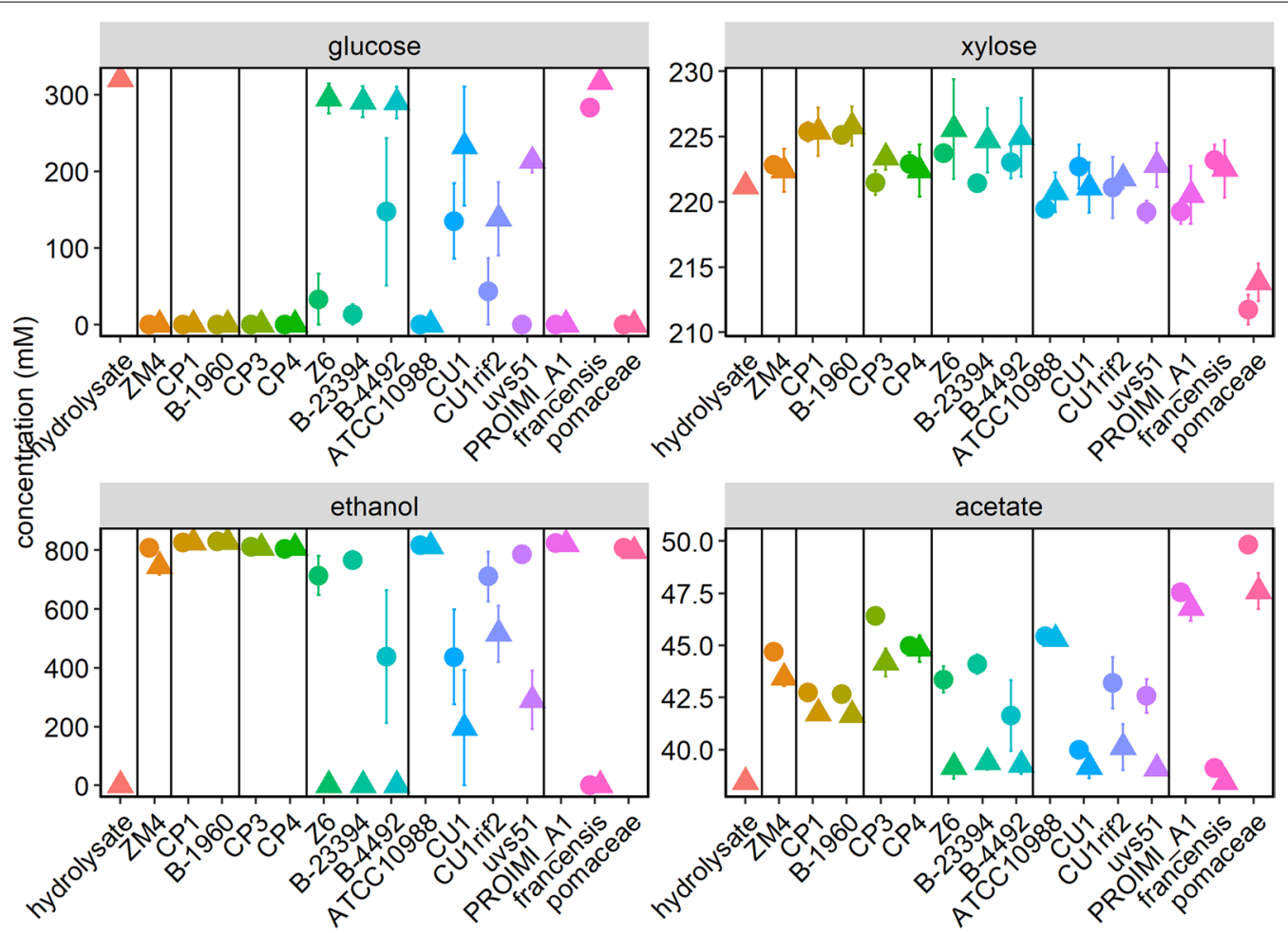

Fig. 5 Metabolite analysis of Zymomonas grown in hydrolysate. Supernatants from the cultures described in Fig. 4 and the initial hydrolysate were analyzed by HPLC for a glucose, b xylose, c ethanol, and d acetate concentrations. Cultures were inoculated to a starting $\mathrm{OD}_{600}$ of 0.1 (triangles) or 0.5 (circles). Points represent the average of three biological replicates and error bars represent standard error 
current level of annotation of the Zymomonas genomes, it is not possible to propose a mechanism. These 41 genes are good candidates for future investigation of glucose tolerance in Zymomonas.

ZM4, the CP1 group, the CP4 group, ATCC10988, PROIMI A1, and pomaceae were able to consume all glucose in the hydrolysate and convert it to ethanol with high efficiency, regardless of inoculation density (Fig. 5). These strains also produced 2 to $8 \mathrm{mM}$ acetate during growth on hydrolysate (initial hydrolysate contained $38.45 \pm 0.05 \mathrm{mM}$ acetate). Strains in the Z6 group consistently required a high inoculum to grow in hydrolysate and convert glucose to ethanol in this condition. One possible cause of the lower hydrolysate tolerance of strains in the Z6 group is that none of the strains contain a homolog of ZM4 ZM0101. This locus encodes a NAD-dependent epimerase/dehydratase and is important for hydrolysate tolerance in ZM4 [30]. The francensis subspecies appeared completely intolerant of hydrolysate and did not grow or significantly ferment glucose at either inoculum level.

All strains except the pomaceae subspecies were incapable of consuming xylose in the hydrolysate. The pomaceae subspecies consumed $10 \mathrm{mM}$ or $\sim 4.7 \%$ of the xylose in the hydrolysate. However, it did not produce more ethanol than ZM4 and rather produced slightly more acetate. Significant efforts have been made to engineer $\mathrm{ZM} 4$ and $\mathrm{CP} 4$ to ferment xylose, therefore a native xylose fermentation pathway in the Zymomonas genus would be of significant interest in the field [33-35]. Although the pomaceae genome contains over 200 genes that do not have homologs in the other Zymomonas genomes, none of these could be clearly linked to xylose metabolism via current annotations. It is also possible that the xylose consumption phenotype results from changes in regulation of genes found in other organisms, considering that ZM4 can be evolved for xylose utilization without expression of heterologous genes [35]. Although the pomaceae subspecies in general does not have optimal characteristics as a biofuel producer, its native xylose utilization capability should be explored further.

\section{Isobutanol tolerance}

Isobutanol (IBA) is an advanced biofuel being pursued for production in several platforms [36-38]. Therefore, we tested the tolerance of the $Z$. mobilis strains to this compound. We first determined the half maximal inhibitory concentration $\left(\mathrm{IC}_{50}\right)$ of IBA with strain ZM4 to develop a protocol for assaying IBA tolerance. We grew ZM4 with a range of IBA concentrations and calculated area under the curve after $8 \mathrm{~h}$ of growth (AUC ${ }_{8}$ ). We used the AUC values to calculate an observed $\mathrm{IC}_{50}$ of $\sim 1 \%$ for ZM4 grown in rich medium in anoxic conditions (Fig. 6a). We then compared the tolerance of all strains to $0.5 \%$ and $1.0 \%$ IBA by measuring the AUC at $8 \mathrm{~h}$ (Fig. 6b). All strains were able to grow in the presence of $1 \% \mathrm{IBA}$, with $\mathrm{AUC}_{8}$, ranging from $\sim 40$ to $80 \%$ of the control without isobutanol. Strains ZM4, Z6, francensis, and pomaceae showed the highest relative growth with 1\% IBA, although the overall growth of the francensis and pomaceae strains was low at $8 \mathrm{~h}$ (Additional file 1: Figure S2). Strains in other groups showed similar tolerance to IBA with Drainas group being the least tolerant. Considering the relatively small differences in isobutanol tolerance, it was not possible to connect specific genes with improved isobutanol tolerance at this time. Because there was an unexpected increase in $\mathrm{AUC}_{8}$ for strain $\mathrm{Z6}$ growth
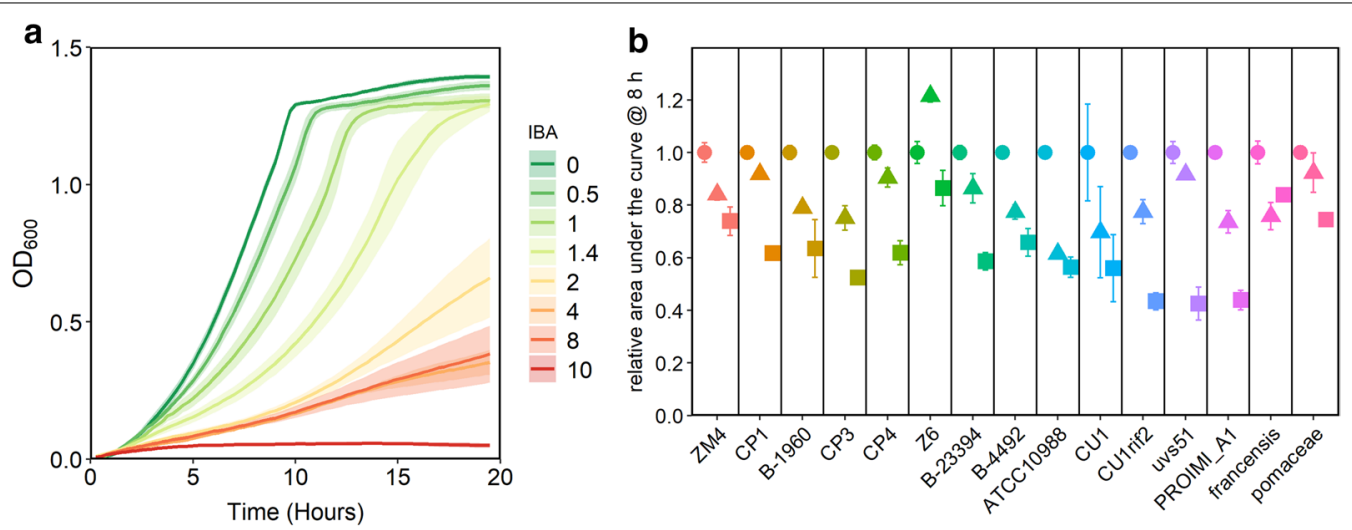

Fig. 6 IBA tolerance of Zymomonas strains. a Growth of ZM4 in rich medium in the presence of 0 to $10 \%(\mathrm{~V} / \mathrm{v})$ IBA. $\mathbf{b}$ growth of Z. mobilis strains in rich medium in the presence of $0.0 \%$ (circles), $0.5 \%$ (triangles), or $1.0 \%$ (squares) IBA. AUC, calculated after $8 \mathrm{~h}$ of growth, with no IBA added is set to 1.0 for each strain and relative AUC is shown for conditions with IBA added. Points or lines represent the average of three biological replicates and error bars or ribbons represent standard error 
with $0.5 \%$ isobutanol, we repeated growth of ZM4 and Z6 with isobutanol in culture tubes. We observed that Z6 did not actually have increased growth with isobutanol and the result in the initial experiment was likely due to an inoculation error (Additional file 1: Figure S3).

\section{Genome methylation analysis and DNA defense systems}

The new genomes presented here were sequenced using a PacBio platform that also detects methylation at each base. The methylation sites for the new genomes were analyzed to predict which types of DNA methylation machinery are present in each strain. All 9 of the newly sequenced genomes showed greater than $99 \%$ methylation at GANTC sites, characteristic of the CcrM (Cell cycle regulated Methyltransferase) system, which has been well-studied in Caulobacter crescentus and other $\alpha$-proteobacteria. This methylation pattern is consistent with prior REBASE predictions for Zymomonas based on the presence of CcrM system genes [39]. The modification methylase (ZMO1005) has been found in all 17 sequenced genomes, with amino acid identity to the ZM4 gene of $99-100 \%$ in subspecies mobilis, 95\% in francensis, and $82 \%$ in pomaceae. CcrM is involved in cell cycle regulation, including transcriptional regulation of cell-cycle control genes, and GANTC sites are overrepresented in intergenic regions in C. crescentus [40]. Further study of the $Z$. mobilis CcrM system is warranted, considering that recent analysis suggests that $Z$. mobilis may contain up to 100 copies of the genome per cell [30,41].

Beyond the GANTC methylation site, several methylation patterns consistent with restriction-modification $(\mathrm{R}-\mathrm{M})$ systems were detected (Table 4). Sites that were methylated with a frequency greater than $99.9 \%$ were usually associated with Type I or Type II R-M systems. In some strains, a few highly similar sequences were detected. These are denoted as 'variable' in Table 4, and all sequence variants are provided in Additional file 1: Table S5. Methylated sequences were shared within the groups of strains (at least 4 within the Drainas group, and two within the Z6 group), probably resulting from the activity of $h s d M$ methylases on the homologous plasmids described above. Some of the Type I methylation sequences were predicted earlier, but only for a few of the previously sequenced genomes (CP4, ZM4 and pomaceae, REBASE [39]).Thus, our methylation analysis together with annotation of Type I R-M genes to specific plasmids is an important addition to the current knowledge of restriction-modification systems in Z. mobilis.

Beyond the Type I and Type II R-M systems detected by methylation analysis, Zymomonas strains have additional DNA defense mechanisms in the form of Type IV restriction and CRIPSR/Cas systems. In 2011, Kerr et al. [43] identified a putative Type IV restriction endonuclease coding gene, $m r r$ (ZMO0028) in ZM4, based on conserved domains with known Mrr proteins using BLASTp. Inactivation of $m r r$ by insertion of a chloramphenicol resistance gene ( $\mathrm{cam})$ resulted in increased transformation efficiency in Z. mobilis ZM4, suggesting that the Mrr protein was responsible for cleaving foreign DNA [43, 44]. Mrr homologues were found in all sequenced genomes except subspecies pomaceae and are all chromosomally located. Sequence identity to the ZM4 gene was 100\% with Drainas group, NCIMB 11163 and CP1, 99\% with PROIMI A1, 97\% with CP4 and 82\% with francensis.

Table 4 Methylation sites for R-M systems in newly sequenced Zymomonas strains

\begin{tabular}{|c|c|c|c|c|c|}
\hline Sequence & Type & Strains & Group & $\% \bmod$ & Notes \\
\hline cCwGg & $\mathrm{m} 4 \mathrm{C}$ & CP1 & & 99.6 & \\
\hline cAcnnnnnaTya & $\mathrm{m} 6 \mathrm{~A}$ & CP1 & & 100 & \\
\hline rgAtcy & $\mathrm{m} 6 \mathrm{~A}$ & CP3 & & 98.6 & \\
\hline craAnnnnnncTc & $\mathrm{m} 6 \mathrm{~A}$ & $\mathrm{CP} 3$ & & 100 & \\
\hline rcgcAg & $\mathrm{m} 6 \mathrm{~A}$ & B-23394, B-4492 & Z6 & $\geq 99.9$ & \\
\hline gcAnnnnnncTga & $\mathrm{m} 6 \mathrm{~A}$ & B-23394, B-4492 & Z6 & 100 & \\
\hline gcAgnnnnnnrta & $\mathrm{m} 6 \mathrm{~A}$ & CU1, CU1 rif2, uvs51 & Drainas & 100 & \\
\hline tAynwnnnnctgc & $\mathrm{m} 6 \mathrm{~A}$ & CU1, CU1rif2, uvs51 & Drainas & 100 & variable in CU1 rif2 \\
\hline bgcAnnwnnntgct & $\mathrm{m} 6 \mathrm{~A}$ & CU1, CU1 rif2, uvs51 & Drainas & 100 & different in CU1 rif2 \\
\hline agcAnnnnnntgc & $\mathrm{m} 6 \mathrm{~A}$ & CU1, CU1rif2, uvs51 & Drainas & 100 & variable in uvs51 \\
\hline Ccggtgncar & $\mathrm{m} 4 \mathrm{C}$ & PROIMI A1 & & 39.1 & \\
\hline gagntCcnntnnnnnaw & $\mathrm{m} 4 \mathrm{C}$ & PROIMI A1 & & 92.9 & \\
\hline cTgcAg & $\mathrm{m} 6 \mathrm{~A}$ & francensis & & 100 & Pstl \\
\hline
\end{tabular}

Capital letters indicate the site of methylation. Methylated bases were detected during sequencing by correlating base incorporation kinetics with base modifications [42]. The methylation motifs were identified using motifMaker software (https://github.com/bioinfomaticsCSU/MultiMotifMaker) 
CRISPR systems have also been detected in Zymomonas previously. Z. mobilis ZM4 has a functional Type I-F CRISPR/Cas system, with Cas3 nuclease/helicase [3]. This CRISPR system has been successfully utilized for genome editing in ZM4 [45]. We observed Cas3 homologs on the chromosomes of all sequenced genomes of subspecies mobilis. Sequence identity with ZM4 Cas3 is $98 \%$ in the CP1 group, PROIMI A1 and NCIMB 11163 , 97\% with the CP4 and Drainas groups, and 95\% with the Z6 group. Z. mobilis pomaceae appears to have Type I-E and I-C CRISPR systems on the chromosome and a $37 \mathrm{~kb}$ plasmid, respectively [3]. Z. mobilis francensis has many genes associated with CRISPR systems, but no homolog to the Cas3 of ZM4 has been found.

\section{Electroporation and conjugation efficiency}

To begin to link the presence of DNA defense systems with physiology, we measured the efficiency of electroporation and conjugation of a plasmid into each of the $Z$. mobilis strains and normalized the efficiency to that of ZM4 (Table 5). We utilized a plasmid (pRL814) that was previously constructed from standard synthetic biology parts for use in Z. mobilis [46, 47]. pRL814 carries a spectinomycin resistance cassette and an IPTG-inducible $g f p$. We found that most strains were not easily transformed with this plasmid by electroporation. We successfully obtained colonies for only 5 strains, ZM4, Z6, B-4492, CP4, and CU1rif2. Two strains in the Z6 group

Table 5 Electroporation and conjugation efficiencies of each strain, relative to ZM4

\begin{tabular}{llll}
\hline Group & Strain & Electroporation & Conjugation \\
\hline ZM4 & ZM4 & 1 & 1 \\
CP1 & CP1 & n.d & n.d \\
& B-1960 & n.d & $7 \times 10^{-2}$ \\
CP4 & CP3 & n.d & $5 \times 10^{-3}$ \\
& CP4 & $0.01 \pm 0.01$ & $1 \times 10^{-2}$ \\
Z6 & B-23394 & n.d & $3 \times 10^{-4}$ \\
& Z6 & $2.15 \pm 0.77$ & $9 \times 10^{-3}$ \\
& B-4492 & $4.78 \pm 2.16$ & $1 \times 10^{-3}$ \\
Drainas & ATCC 10988 & n.d & $1 \times 10^{-3}$ \\
& CU1 & n.d & $5 \times 10^{-3}$ \\
& CU1 rif2 & 0.25 & $4 \times 10^{-4}$ \\
& uvs51 & n.d & $2 \times 10^{-2}$ \\
None & PROIMl A1 & n.d & $2 \times 10^{-3}$ \\
& francensis & n.d & $n . d$ \\
& pomaceae & n.d & $n . d$ \\
\hline
\end{tabular}

Efficiency of electroporation for ZM4 was 15 CFU per $1 \mu \mathrm{g}$ of pRL814 DNA. Efficiency of conjugation was $1.25 \times 10^{-4}$ calculated as number of spectinomycin-resistant colonies divided by number of colonies on plates without spectinomycin

n.d. not detected had slightly higher electroporation efficiencies than ZM4, while CP4 and CU1rif2 had significantly lower electroporation efficiencies. Conjugation of the same plasmid from E. coli WM6026 into these strains was more successful. We obtained transconjugants carrying the plasmid for 12 out of 15 strains tested. In the case of conjugation, ZM4 clearly had the highest efficiency, with all other strains having a 10 - to 1000 -fold lower electroporation efficiencies. Overall, the ZM4 and Z6 groups were the most amenable to DNA uptake, with Z6 strains having slightly higher electroporation efficiency and ZM4 having significantly higher conjugation efficiency. We did not successfully introduce a plasmid into the francensis and pomaceae strains by either method. Specific method development for these subspecies is likely necessary to enable their engineering. Recent efforts to enhance the transformability of ZM4 by removing restriction-modification systems have been highly successful and a modified ZM4 strain has been developed with $3 \mathrm{R}-\mathrm{M}$ systems and the CRISPR-Cas system inactivated. This strain has a much higher conjugation efficiency than the parent strain with several plasmids tested (personal communication, Patricia Kiley, University of Wisconsin, Madison). Overall, the low conjugation and electroporation efficiencies we observed are consistent with the large number of genome defense systems detected in all genomes. Because a high level of DNA defense appears to be a common trait across the genus, further modification to improve ZM4 as a chassis appears to be a more promising strategy than screening for strains with a higher natural competency.

\section{Variability in cellulose synthase operon and promoter}

$Z$. mobilis strains have a tendency to flocculate, a trait that can be beneficial for bioprocessing [20, 48], but challenging for genetic modification and other laboratory protocols [49]. Floc formation by Z. mobilis ZM4, $\mathrm{CP} 4$ and their flocculating variants is driven by the production of extracellular cellulose fibrils, which become entangled and bind cells into flocs up to $4 \mathrm{~mm}$ in length $[50,51]$. Several potential flocculation triggers have been reported, including high ethanol concentration, minimal medium, and oxygen, but overall, regulation of flocculation remains unclear $[52,53]$. We identified three strains with naturally flocculating phenotypes: two strains in the CP1 group, and Z. mobilis subspecies francensis (Fig. 3c). To better understand the regulation of floc formation, we compared flocculating strains and ZM4 under a range of growth conditions, varying oxygen availability, shaking, and medium type (Fig. 7). The final $\mathrm{OD}_{600}$ of cultures grown in different conditions is shown in (Additional file 1: Figure S4. To measure flocculation, we fully resuspended stationary phase cultures by harsh vortexing, 


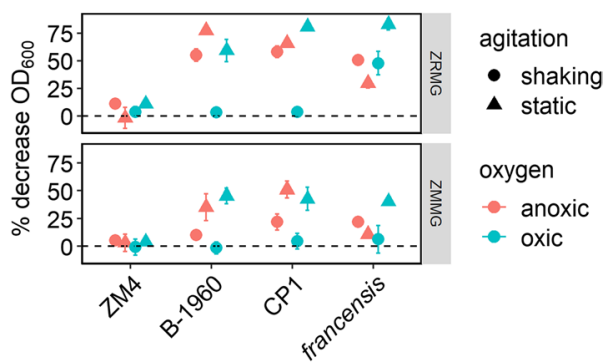

Fig. 7 Flocculation of Zymomonas strains. Identical volume of the same colony resuspended in ZMMG was used to inoculate $5 \mathrm{ml}$ of ZMMG or ZRMG. Cultures were grown for $48 \mathrm{~h}$ statically or with shaking in aerobic or anaerobic conditions as described in "Materials and methods". After this time flocs were dispersed by vortexing, and $\mathrm{OD}_{600}$ was measured by removing $100 \mu \mathrm{l}$ from the top of the culture to $0.9 \mathrm{ml}$ of medium immediately and after $45 \mathrm{~min}$ of standing on a bench. Results shown are average of three independent experiments. Points represent the average of three biological replicates and error bars represent standard error

allowed them to re-flocculate and settle for $45 \mathrm{~min}$, then measured the decrease in $\mathrm{OD}_{600}$ in the top $100 \mu \mathrm{L}$ after settling. A greater \% decrease in $\mathrm{OD}_{600}$ indicates more settling, and therefore, a greater degree of flocculation. Although PROIMI A1 was previously described as a flocculating strain, it formed only delicate, easy-to-disperse flocs under these experimental conditions, therefore it was not included in this analysis. We observed that ZM4 exhibited little flocculation under any tested condition, although flocculation has been observed for this strain previously [53]. Overall patterns of flocculation were similar between the other three strains, with increased flocculation in rich medium and static cultures. Oxygen did not appear to be a major driver of flocculation, except in the case of the francensis subspecies, for which oxygen exposure promoted flocculation. The greater effect of mechanical disruption than oxygen or medium suggested that the flocculating phenotypes were constitutive and probably determined by major changes in cellulose synthesis rather than more subtle changes at the regulatory level. To ensure that floc formation of all strains was due to cellulose fibril synthesis, we also treated cultures of CP1, B-1960, and francensis with cellulase and found that this completely dispersed the flocs, indicating that all strains tested here use the same flocculation mechanism as other Zymomonas strains (data not shown).

Cellulose synthesis is required for floc formation in $Z$. mobilis ZM4, CP4, and flocculating variants and production of cellulose fibrils is performed by the cellulose synthase complex encoded by the $b c s$ operon $[50,51]$. Strains bearing Tn5 insertions in $b c s$ genes or with the entire operon deleted are not able to form flocs during aerobic growth in rich or minimal media [30, 49, 53]. Several highly flocculent strains have been described previously: PROIMI A1, ATCC 31822 (ZM401) and B-12526, a flocculating derivative of $\mathrm{CP} 4$. However, little work has been done to identify the genetic differences leading to the flocculating phenotype. Using Multiple Sequence Alignment (Clustal $\Omega$ ), we compared bcs operons and their regulatory regions for 18 genomes to find differences between flocculating and non-flocculating strains. We added ZM401, which was not included in the general genome comparison, to this analysis.

Two transcription start sites (TSS) for the bcs operon at -26 and -23 have been identified upstream of ZMO1080 in ZM4 [54]. We identified and analyzed regulatory elements upstream of the TSS (Additional file 1: Figure S5) and found that a 177-nt region upstream of ZMO1080 was mostly invariable within $Z$. mobilis mobilis strains. Single nucleotide substitutions in the Z6 group seem irrelevant for flocculation and a single-nucleotide deletion in PROIMI A1 is unlikely to affect regulation (Additional file 1: Figure S5C). Subspecies francensis and pomaceae showed significant variability from $Z$. mobilis mobilis and each other within the region. TSSs of the $b c s$ operon in these strains must be identified separately. Overall, it appears unlikely that differences in the promoter region contribute to differences in flocculation between strains.

There are 6 genes in the bcs operon of Z. mobilis: two coding for hypothetical proteins (ZMO1080, $\mathrm{ZMO1081)}$ and four genes with known functions (bcs$A B C Z$, ZMO1083-1086). BcsA encodes a catalytic subunit anchored in the inner membrane with the catalytic center and regulatory PilZ domain in the cytosol. BcsA requires c-di-GMP bound to the PilZ domain for activity. $\mathrm{BcsB}$ is a periplasmic subunit anchored in the inner membrane. The BcsAB complex is found in all bacterial cellulose synthase operons and is indispensable for cellulose synthesis. BcsC is composed of an N-terminal periplasmic domain and $\mathrm{C}$-terminal $\beta$-barrel forming a channel in the outer membrane for cellulose secretion. The N-terminal domain has multiple TPR (tetratricopeptide repeat) domains and is thought to organize function of the entire complex. Finally, BcsZ is a gluconase, which is required for proper formation of fibrils. ZMO1080 and ZMO1081 are highly conserved within Zymomonas mobilis and ZMO1081 shares homology with $b c s Q$ from other Proteobacteria. ZMO1080 appears to be specific for Z. mobilis. Given their high conservation, these two genes are likely important for cellulose synthase function, but their roles have yet to be determined.

Unlike the promoter regions, $b c s A$ genes were much more variable within Zymomonas. Clustal $\Omega$ alignment revealed significant length and sequence variability of Bcs proteins in pomaceae and francensis compared to 
Z. mobilis mobilis and the $b c s A$ gene was not annotated in pomaceae. Thus, although we identified francensis as a flocculating strain, we were not able to attribute this phenotype to any specific gene within the bcs operon. Protein alignment of BcsA within the mobilis subspecies identified differences specific for one or more of the flocculating strains (Additional file 2: Figure S6). In PROIMI A1, a 465-nucleotide deletion at the junction of $b c s A$ and $b c s B$ results in truncated forms of both proteins. Adding the sequence of BcsA from Rhodobacter sphaeroides (for which the 3D crystal structure has been resolved [55]) to the alignment showed that the truncated BcsA lacks part of the PilZ domain that participates in binding c-di-GMP (Additional file 3: Figure S7). It seems likely that activity of cellulose synthase in PROIMI A1 has been deregulated by this deletion, possibly resulting in the constant but weak floc formation.

Sequence comparison of 26 genes differentially expressed in ZM401 compared to ZM4, did not reveal any differences in $b c s A$ or $b c s B$ genes or their upstream regions [56]. However, in independent research Xia et al. [50] found a single-nucleotide deletion (T) in $b c s A$ of ZM401 as compared to ZM4 and suggested that bcsA401 was fused to the upstream gene. This would result in a longer protein with an additional transmembrane helix compared with BcsA of ZM4. Our protein alignment of BcsA from ZM401 to other Z. mobilis mobilis strains showed a protein of the same length as in the other 12 strains (Additional file 2: Figure S6), revealing that rather than a $\mathrm{T}$ deletion in ZM401, there is a $\mathrm{T}$ insertion in ZM4. We confirmed one T insertion after A172 in $b c s A$ from ZM4 by Sanger sequencing. Thus, ZM4 $b c s A$ is a pseudogene as annotated in NCBI data base. It is uncertain why ZM4 can still flocculate in certain conditions. Because the additional $\mathrm{T}$ was inserted within a stretch of 8 thymidine nucleotides, it is possible that a ribosomal shift or RNA polymerase slippage can occasionally lead to synthesis of full-length BcsA in ZM4, thus providing some cellulose synthesis apparently sufficient to cause flocculation under specific conditions [53].

As described above, we found that two strains from subspecies mobilis, B-1960 and CP1, showed strong flocculation in all tested conditions. Protein alignment identified four single amino acid substitutions in BcsA that are specific for these two strains (Y408H, W452S, T519I, and F645V, Fig S5). The first three residues are conserved in Zymomonas mobilis and corresponding residues of $R$. sphaeroides BcsA (W418, L462, T528, Additional file 3: Figure S7) are located in transmembrane helices where they may assist in passage of cellulose through the inner membrane. It is possible that these mutations affect efficiency of cellulose export and result in increased flocculation. BcsB showed less variability across Zymomonas except that in B-12526 it is a pseudogene and in PROIMI A1 it is truncated from $\mathrm{N}$-terminus ( $\Delta 61$ aa). As both these strains are naturally flocculating, it is possible that these changes contribute to flocculation.

In three flocculating strains (CP1, B-1960 and ZM401), we identified insertion of two serines in $\mathrm{Bcs} C$ (S818-819), resulting in seven serines in a row versus four or five in other strains (Additional file 4: Figure S8). This stretch of serines is located within the periplasmic $\mathrm{N}$-terminal part of BcsC. P. aeruginosa AlgK, a functional homolog of the $\mathrm{BcsC} \mathrm{N}$-terminal domain, organizes the function of the entire Bcs secretion complex [57]. It is possible that in Zymomonas the $\mathrm{N}$-terminus of $\mathrm{BcsC}$ has a similar function and thus mutations within this region may lead to altered cellulose transport and subsequent flocculation.

Overall comparison of the Bcs operons and their promoter regions across $18 \mathrm{Z}$. mobilis strains showed that the promoter region is highly conserved while genes encoding cellulose synthase subunits display significant changes, including gene fusions, pseudogenes, and amino acid substitutions. Some changes within the $b c s$ genes were specific to the flocculating strains, at least in one case affecting a regulatory domain, possibly leading to the flocculation phenotype appearing across all conditions. Our analysis suggests that flocculation is regulated primarily at the post-translational level in Z. mobilis and efforts to implement transcriptional control of this trait are not likely to be successful.

\section{Regulation of flocculation by diguanylate cyclases/ phosphodiesterases}

Bacterial Bcs complexes are positively regulated by cyclic di-GMP. Four GG(D/E)EF motif-containing diguanylate cyclases have been identified in ZM4 [53]. Two were previously linked to flocculation phenotypes; a $\operatorname{Tn} 5$ insertion in a diguanylate cyclase (ZMO0919) abolished flocculation of ZM4 in oxic minimal media while another diguanylate cyclase, ZMO1055 was upregulated in ZM401 as compared to ZM4. The single amino acid substitution A525V in the latter was proposed to cause flocculation [56]. We compared sequences of both genes and their promoter regions to see if there are any differences, which could lead to higher activation of BcsA in flocculating strains. There were two TSS reported at -27 and -38 of ZMO0919 gene and TSS at -119 of ZMO1055 [54]. Similar to the $b c s$ operon, we found that the regulatory regions are highly conserved across subspecies mobilis with just one nucleotide deletion in two strains in the Drainas group. This mutation seems irrelevant to flocculation as we did not observe any differences between the four strains in this group. Other single-nucleotide substitutions are group-specific (Z6 or CP4) and not related to flocculation. The diguanylate cyclase genes were more 
variable; we found that in Drainas group ZMO1019 was split into two pseudogenes by insertion of a transposase. In NCIMB 11163, this locus acquired a stop codon and is annotated as a pseudogene. We also found a V430I substitution in flocculating strains CP1, B-1960 and PROIMI A1 (not shown). ZMO1055 showed even more variability within $Z$. mobilis mobilis. In the $\mathrm{Z} 6$ group and $\mathrm{CP} 1$ it is a pseudogene. We confirmed that the A525V substitution observed by Jeon et. al. [56] is unique for ZM401 as is A571T in PROIMI A1, both located in the N-terminus of the protein (not shown). Some diguanylate cyclases can substitute for each other, but recent findings show that only some regulate BcsA [58]. Our analysis shows that all flocculating strains have ZMO0919 while ZMO1055 is carrying mutations in PROIMI A1 and ZMO401 and is non-functional in the CP1 group (pseudogene). We speculate that the ZMO0919 diguanylate cyclase is more active in regulating $\mathrm{BcsA}$ and it is also possible that mutated versions of ZMO1055 acquired higher activities. We expect that future functional studies will shed additional light on the regulation of flocculation by diguanylate cyclases/phosphodiesterases.

\section{Conclusion}

We described the present Zymomonas genomic diversity and compared bioenergy-relevant traits of 15 Zymomonas strains which revealed that strain ZM4 had the highest isobutanol tolerance, hydrolysate tolerance, and conjugation efficiency. Considering the low overall diversity observed within the genus, we propose that future efforts should focus on further developing one or a few strains via synthetic biology methods, rather than exploration of additional Zymomonas isolates. For example, several DNA defense systems were present in all strains, suggesting that low natural competence is a trait common to the entire genus. Based on our physiological characterization, we propose that ZM4 should be further developed into the model organism and platform strain for the genus. Some other strains had promising traits that should be studied further for potential transfer to ZM4, particularly the capability of the pomaceae strain to consume xylose in lignocellulosic hydrolysate.

\section{Methods}

\section{Sequencing of Zymomonas genomes}

The draft genomes of Zymomonas mobilis strains sequenced for this study were generated at the DOE Joint Genome Institute (JGI) using the Pacific Biosciences (PacBio) sequencing technology [59]. A > $10 \mathrm{kbp}$ Pacbio SMRTbellTM library was constructed and sequenced on the PacBio Sequel platform. All general aspects of library construction and sequencing performed at the JGI can be found at http://www.jgi.doe.gov. The raw reads were assembled using HGAP [smrtlink/6.0.0.47835, HGAP 4 (0.2.1)] [60]. Additional file 1: Table S1 contains sequencing information for each genome, including filtered subreads, total bp, number of contigs and scaffolds in the final draft assembly, and genome size and input read coverage. DNA modification detection and motif analysis were performed using PacBio SMRT analysis platform (pbsmrtpipe.pipelines.ds modification motif analysis 0.1.0). Briefly, raw reads were filtered using SFilter, to remove short reads and reads derived from sequencing adapters. Filtered reads were aligned to the reference genome using BLASR (v5.3) [61]. Modified sites were then identified through kinetic analysis of the aligned DNA sequence data [42]. Modified sites were then grouped into motifs using MotifFinder2. These motifs represent the recognition sequences of methyltransferase genes active in the genome [62].

\section{Phylogenetics of Zymomonas genomes Marker gene trees}

A concatenated marker gene tree was constuctued using all 17 Zymomonas genomes together with 5 Sphingomonas genomes used as outgroup. The marker gene tree consists of 56 universal single copy genes and was produced by extracting these marker genes from each genome using hmmsearch (version 3.1b2). For each marker, alignments were constructed with MAFFT [63], trimmed with trimAl 1.4 [64], then concatenated into a single alignment. Maximum likelihood phylogenies were constructed with IQ-TREE [65], using the WAG substitution model and 1000 bootstraps. Trees were visualized with ggtree [66].

\section{SNP trees}

To generate the SNP tree, we followed a similar pipeline to the one found in [16], where each genome was aligned to a reference genome (highest quality genome in the set). SNPs were identified based on the Nucmer alignment output from the MUMmer package [67], concentated, followed by neighbor joinging tree construction. Trees were rooted on the two outlying genomes: francensis and pomaceae, and visualized with ggtree [66].

\section{Genome clustering}

Genome clustering was performed with two different approaches, the hierBAPS bayesian clustering analysis and clustering based on 99\% average nucleotide identity (ANI). First for hierBAPS clustering, we employed a package integrated into $\mathrm{R}$ called RhierBAPS, Tonkin-Hill et al. 2018 which is an $\mathrm{R}$ implementation of the BAPS algorithm (Bayesian Analysis of Population Structure) [18], designed to identify subspecies genome clusters. Input for this software was the same whole genome 
alignment used in the SNP tree. Annother approach to unravel genetic relationships from the 17 Zymomonas genomes was to perform pairwise ANI clustering of all genomes at $99 \%$ similarity. To do this we used fastANI [68], filtered to an alignment fraction $>70 \%$, then clustered into $>99 \%$ ANI clusters using mcl [69].

\section{Orthologue clustering and analysis of gene content}

Genes were called and annotated based on the Integrated Microbial Genomes (IMG) system at the DOE Joint Genome Instittute [70]. Naming of genes and contigs follows the IMG nomenclature. To cluster genes into gene families/orthologue groups, all genomes were passed into OrthoFinder [71]. Following clustering, genes were identified as belonging to the Core, Accessory or Singleton genomic components. For a gene to be considered core, it had to be identified in all 17 of the analyzed genomes. We merged the orthologue data together with the annotation data and provide as a supplemental file (Additional file 5: Table S6). A single rarefaction curve was generated based on the random resampling of the pool of unique gene family/orthologue groups, and a Venn diagram was created to assess shared and unique orthologues, both plotted in R.

\section{Phenotypic characterization of Zymomonas strains Growth media and chemicals}

LB medium (Miller, Accumedia) was used to grow $E$. coli strains. ZRMG medium (1\% yeast extract, $2 \%$ glucose, and $15 \mathrm{mM} \mathrm{KH}_{2} \mathrm{PO}_{4}$ ) or ZMMG medium (1.0 g $\mathrm{KH}_{2} \mathrm{PO}_{4}, 1.0 \mathrm{~g} \mathrm{~K}_{2} \mathrm{HPO}_{4}, 0.5 \mathrm{~g} \mathrm{NaCl}, 1.0 \mathrm{~g}\left(\mathrm{NH}_{4}\right)_{2} \mathrm{SO}_{4}$, $0.2 \mathrm{~g} \mathrm{MgSO}_{4} \times 7 \mathrm{H}_{2} \mathrm{O}, 0.025 \mathrm{~g} \mathrm{Na}_{2} \mathrm{MoO}_{4} \times 2 \mathrm{H}_{2} \mathrm{O}, 0.025 \mathrm{~g}$ $\mathrm{FeSO}_{4} \times 7 \mathrm{H}_{2} \mathrm{O}, 0.010 \mathrm{~g} \mathrm{CaCl} \times 2 \mathrm{H}_{2} \mathrm{O}, 0.001 \mathrm{~g}$ calcium pantothenate, $20.0 \mathrm{~g}$ D-glucose per $1 \mathrm{~L}$ ) was used to grow $Z$. mobilis. ZMMG medium was prepared from pre-autoclaved $10 \times$ base solution $\left(\mathrm{KH}_{2} \mathrm{PO}_{4}, \mathrm{~K}_{2} \mathrm{HPO}_{4}\right.$, $\left.\mathrm{NaCl},\left(\mathrm{NH}_{4}\right)_{2} \mathrm{SO}_{4}\right), 1000 \times$ solutions of metal supplements and $10 \times \mathrm{D}$-glucose. $1000 \times$ concentrated calcium pantothenate was sterilized by filtration. All components were mixed, let stand for $45 \mathrm{~min}$ and filtered through a $0.22-\mu \mathrm{m}$ filtering device. Solid media also contained $15 \mathrm{~g}$ of agar (Difco) per $1 \mathrm{~L}$. Zymomonas recovery medium (ZRecM) contained $0.5 \%$ yeast extract, $1 \%$ tryptone, $0.025 \% \mathrm{MgSO}_{4}, 0.25 \%\left(\mathrm{NH}_{4}\right)_{2} \mathrm{SO}_{4}, 0.5 \%$ glucose and $1.5 \mathrm{mM} \mathrm{KH}_{2} \mathrm{PO}_{4}$. When indicated, diaminopimelic acid (DAP) was added to final concentration of $0.1 \mathrm{mM}$. Spectinomycin was added to a final concentration of $100 \mu \mathrm{g} / \mathrm{mL}$ or $50 \mu \mathrm{g} / \mathrm{mL}$ for Z. mobilis and E. coli cultures, respectively. Ammonia fiber expansion-treated hydrolysate (6\% Glucan AFEX Switchgrass Hydrolysate (ASGH) year 2010) was from Great Lakes Bioenergy
Research Center, Madison, Wisconsin, and isobutanol was from Sigma-Aldrich.

\section{Bacteria and plasmids}

Zymomonas mobilis ATCC 31821 (ZM4) was from American Type Culture Collection (ATCC). NRRL B-1960, NRRL B-4286, NRRL B-4490, NRRL B-4492, NRRL B-14022, NRRL B-14023, NRRL B-23394, and NRRL B-23393 were obtained from USDA Agricultural Research Service Culture Collection (ARS). DSM 424, DSM 12495, DSM 12494, DSM 12497, DSM 14017, and DSM 18599 were from German Collection of Microorganisms and Cell Cultures (DSMZ). E. coli WM6026 (lacIq rrnB3 $\Delta$ lacZ4787 hsdR514 $\triangle$ araBAD567 $\Delta$ rhaBAD568 rph- $\Delta a t t \Delta::$ pAE12 (DoriR6K-cat:: Frt5), $\Delta$

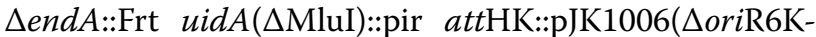
cat::Frt5; trfA::Frt) $\Delta d a p A:: F r t),[72]$ and broad host range plasmid pRL814 containing a spectinomycin resistance gene (aadA1) [46] were gifts from Dr. Patricia Kiley and Dr. Robert Landick (University of Wisconsin, Madison), respectively. pRL814 was propagated and purified from E. coli Mach1 (ThermoFisher Scientific).

\section{Growth conditions}

Growth kinetics was performed using a plate reader (BioTek Synergy H1) in anaerobic chamber (Coy Laboratory Products). Overnight cultures in $5 \mathrm{~mL}$ of ZRMG were inoculated from single colonies grown on ZRMG plates anaerobically. The cultures were grown statically to early stationary phase $\left(\mathrm{OD}_{600}\right.$ around 1.0$)$. The starter cultures were diluted to $\mathrm{OD}_{600} 0.1$ with fresh ZRMG and wells of 96-well microtiter plates were filled with $150 \mu \mathrm{l}$ of each culture in triplicates. The side wells of the plate were filled with ZRMG to minimize evaporation. Cells were grown at $30{ }^{\circ} \mathrm{C}$ with shaking for $20 \mathrm{~h}$, and $\mathrm{OD}_{600}$ measurements were taken every 15 min. Doubling times were calculated from growth curves using the package "growthcurver" in R [28].

\section{Conjugation efficiency}

Conjugation was performed as described in Felczak et al. [47] except that the E. coli strain WM6026 was used as a donor of pRL814. Briefly, Z. mobilis strains were inoculated from a single colony and grown in $5 \mathrm{ml}$ of ZRMG media statically in 14-ml tubes at $30{ }^{\circ} \mathrm{C}$. WM6026 was grown overnight in LB supplemented with diaminopimelic acid (DAP) and spectinomycin at $37{ }^{\circ} \mathrm{C}$. In the morning WM6026 culture was diluted to $\mathrm{OD}_{600} 0.2$ in LB with DAP but without the antibiotic and grown at $30{ }^{\circ} \mathrm{C}$ to $\mathrm{OD}_{600} 1.0$. Overnight culture of $\mathrm{Z}$. mobilis was diluted to $\mathrm{OD}_{600} 1.0$ and $0.9 \mathrm{ml}$ was mixed with $0.9 \mathrm{ml}$ of WM6026 at $\mathrm{OD}_{600} 1.0 \mathrm{in} 2.0 \mathrm{ml}$ Eppendorf 
tubes. Bacteria were centrifuged at $17,000 \times \mathrm{g}$ for $30 \mathrm{~s}$ in microcentrifuge at room temperature. Supernatant was decanted and the pellet let stand for $3 \mathrm{~min}$. Loosened pellet was placed as a one drop in the center of plate containing solid ZRMG supplemented with $0.1 \mathrm{mM}$ DAP and tryptone $(10 \mathrm{~g} / \mathrm{L})$. Plates were incubated overnight at $30^{\circ} \mathrm{C}$. Next day cells were scraped into $1.5-\mathrm{ml}$ Eppendorf tube, $1 \mathrm{ml}$ of ZRMG was added and cultures incubated for $5 \mathrm{~h}$ at $30{ }^{\circ} \mathrm{C}$. After this time, $100 \mu \mathrm{l}$ of undiluted or diluted (10 or 100 times) culture was spread on ZRMG with spectinomycin. $100 \mu \mathrm{l}$ from serial dilutions in duplicate were spread on ZRMG plates without spectinomycin. Plates were incubated at $30{ }^{\circ} \mathrm{C}$ for $48 \mathrm{~h}$ for CFU or 4 days for exconjugants. Efficiency of conjugation was calculated as ratio of exconjugants to $\mathrm{CFU} / \mathrm{ml}$.

\section{Electroporation efficiency}

pRL814 was introduced to Z. mobilis by electroporation. Electrocompetent cells were prepared as follows. $125 \mathrm{ml}$ of ZRMG was inoculated from a single colony and cells were grown overnight in $125 \mathrm{ml}$ bottles, loosely covered, at $30{ }^{\circ} \mathrm{C}$ until $\mathrm{OD}_{600} 0.4$ (microaerobic conditions). Bottles were chilled on ice for over $30 \mathrm{~min}$ and bacteria were spun at $4000 \times \mathrm{g}$ for $15 \mathrm{~min}$ at $4{ }^{\circ} \mathrm{C}$. Pellets were resuspended in equal volume of ice-cold $\mathrm{MQ} \mathrm{H}_{2} \mathrm{O}$ and left on ice for $10 \mathrm{~min}$. After this time, bacteria were spun as above. Washing was repeated one more time with half of the initial volume of ice-cold $\mathrm{MQ} \mathrm{H}_{2} \mathrm{O}$. After spinning as above cells were resuspended in $10 \mathrm{ml}$ of ice-cold $10 \%$ glycerol and centrifuged at $4000 \times \mathrm{g}$ for $10 \mathrm{~min}$ at $4{ }^{\circ} \mathrm{C}$. Final pellets were resuspended gently in $150 \mu$ l of ice-cold $10 \%$ glycerol and used immediately for electroporation as follows. $0.5-1 \mu \mathrm{g}$ of plasmid DNA was mixed with $40 \mu \mathrm{l}$ of electrocompetent cells. Electroporation was in 0.1$\mathrm{mm}$ cuvettes in Micro Pulser (BioRad) set at EC-1. Cells were immediately resuspended in $1 \mathrm{ml}$ of pre-warmed ZRecM and incubated statically at $30{ }^{\circ} \mathrm{C}$ for $5 \mathrm{~h} .100 \mu \mathrm{l}$ from undiluted or 10 times diluted electroporations was spread on ZRMG plates supplemented with spectinomycin. Plates were protected with parafilm from drying and incubated at $30^{\circ} \mathrm{C}$ aerobically, for 4 days or longer until colonies appeared. Serial dilutions were plated on ZRMG without antibiotic to measure survival after electroporation. Efficiency of electroporation was calculated per $1 \mu \mathrm{g}$ of plasmid DNA.

\section{Growth on AFEX hydrolysate}

$\mathrm{pH}$ of AFEX hydrolysate was adjusted to 5.8 with $10 \mathrm{M}$ $\mathrm{NaOH}$. The hydrolysate was filtered through $22-\mu \mathrm{m}$ filter device (VWR) and stored in anaerobic chamber. Z. mobilis cultures were inoculated from fresh ZRMG plates and grown anaerobically in $10 \mathrm{~mL}$ of ZRMG overnight to OD 1-2 in anaerobic chamber. $\mathrm{OD}_{600}$ was measured and cells were concentrated to $\mathrm{OD}_{600} 10$ by centrifuging cells at $8,000 \mathrm{rpm}$ for $10 \mathrm{~min}$ (Sorval ST8, Thermo Scientific) at room temperature, followed by resuspending in appropriate volume of the hydrolysate. $5 \mathrm{~mL}$ of hydrolysate in Hungate tubes was inoculated to $\mathrm{OD}_{600} 0.1$ or 0.5 under anaerobic chamber and tubes were capped and sealed. Tubes were incubated outside the chamber at $30{ }^{\circ} \mathrm{C}$ with shaking for $50 \mathrm{~h}$. After this time, $\mathrm{OD}_{600}$ of 10 times diluted cultures was measured and samples were saved and stored at $-20^{\circ} \mathrm{C}$ for analysis by HPLC.

\section{Isobutanol tolerance}

On cultures in $5 \mathrm{ml}$ of ZRMG were inoculated from single colonies and grown overnight in anaerobic chamber to stationary phase. Cultures were diluted to $\mathrm{OD}_{600} 0.1$ in fresh anaerobic ZRMG. Isobutanol was added to indicated final concentration, mixed and aliquots of $150 \mu \mathrm{l}$ were loaded in triplicate to 96 -well plate. Incubation was performed with shaking at $30{ }^{\circ} \mathrm{C}$ until growth reached saturation [18 h]. IC 50 for ZM4 was calculated from \% growth inhibition by $0.25-10 \%$ IBA calculated as area under curve (AUC) after $8 \mathrm{~h}$ of incubation using online IC 50 calculator (https://www.aatbio.com/tools/ic50calculator). Tolerance of $Z$. mobilis strains to $0.5 \%$ and $1 \%$ IBA was calculated similarly from AUC after $8 \mathrm{~h}$.

\section{Flocculation}

Single colony from ZRMG plate grown anaerobically for $48 \mathrm{~h}$ was suspended in $200 \mu \mathrm{l}$ of ZMMG. $40 \mu \mathrm{l}$ was used to inoculate $5 \mathrm{ml}$ of ZMMG or ZRMG in duplicate for subsequent aerobic or anaerobic growth. For static conditions, cultures were grown in 14-mL plastic tubes in an aerobic environment or an anaerobic chamber. For shaking conditions, cultures were grown with shaking at $275 \mathrm{rpm}$ in Hungate tubes closed with a butyl rubber stopper or loosely covered with aluminum foil for anaerobic and aerobic growth, respectively. For the anaerobic condition, anoxic medium was dispensed into the tubes in an anaerobic chamber and the tubes were capped before removal to ensure an anoxic environment. Cultures were grown for $48 \mathrm{~h}$. Cultures were vortexed until visible flocs disappeared (usually 5-10 s) and $\mathrm{OD}_{600}$ was measured immediately, and again after standing for $45 \mathrm{~min}$ on a bench. Each time $100 \mu \mathrm{l}$ from the top of the culture was removed to $0.9 \mathrm{ml}$ of media for measurement.

\section{Chromosomal DNA purification}

For the novo genome sequencing, $Z$. mobilis strains were grown to stationary phase in $100 \mathrm{ml}$ of ZRMG at $30{ }^{\circ} \mathrm{C}$, statically in anaerobic chamber. Cells were harvested by centrifugation at $6,000 \mathrm{rpm}$ for $10 \mathrm{~min}$ at $4{ }^{\circ} \mathrm{C}$ (Sorval ST8, Thermo Scientific). Genomic DNA was purified as described by Neumann, et al. [73] with some 
modifications. Briefly, pelleted cells were washed with $100 \mathrm{ml}$ of $0.1 \mathrm{M} \mathrm{NaCl}$, centrifuged as above and resuspended in $5 \mathrm{ml}$ of SET buffer $(75 \mathrm{mM} \mathrm{NaCl}, 25 \mathrm{mM}$ EDTA, $20 \mathrm{mM}$ Tris $\mathrm{pH}$ 7.5). Lysozyme was added to final concentration of $1.0 \mathrm{mg} / \mathrm{ml}$ and incubated at $37{ }^{\circ} \mathrm{C}$ for $20 \mathrm{~min}$. RNase A (Sigma), was added to a final concentration of $0.3 \mathrm{mg} / \mathrm{ml}$ and mixture was incubated for $20 \mathrm{~min}$ at $37^{\circ} \mathrm{C}$. After this time, SDS and Proteinase $\mathrm{K}$ were added to final concentrations of $1 \%$ and $1.0 \mathrm{mg} /$ $\mathrm{ml}$, respectively, and incubated at $55{ }^{\circ} \mathrm{C}$ for $2 \mathrm{~h}$. After this time, 0.4 volume of $5.0 \mathrm{M} \mathrm{NaCl}$ was added to a clear, viscous cell lysate and mixed gently. An equal volume of chloroform was added and the mixture was incubated at RT for $30 \mathrm{~min}$, on a swinging platform. After this time, phases were separated by spinning for $15 \mathrm{~min}$ at $8000 \mathrm{rpm}$ at room temperature (Sorval ST8, Thermo Scientific). Clear water phase was collected into a new $15-\mathrm{ml}$ conical tube and equal volume of isopropanol was added. The precipitated DNA was collected by wrapping around Pasteur pipette and submerged in $70 \%$ ethanol to wash out the residual water. DNA was transferred to Eppendorf tube, let dry at room temperature, resuspended in $200 \mu \mathrm{l}$ of TE buffer $(10 \mathrm{mM}$ Tris $\mathrm{HCl} \mathrm{pH} \mathrm{8.0,}$ $1 \mathrm{mM}$ EDTA) and left in $4{ }^{\circ} \mathrm{C}$ overnight. Quality of the DNA was checked by electrophoresis on $0.7 \%$ agarose alongside lambda DNA standard (Thermo Scientific), and RNase A treatment was repeated when necessary followed by ethanol precipitation as described [74]. $\mathrm{A}_{260} /$ $\mathrm{A}_{280}$ and $\mathrm{A}_{260} / \mathrm{A}_{230}$ was measured by nanodrop assay and the final concentration of DNA was determined by fluorometric method (Qubit). Finally, identity of the isolated DNA was confirmed by16S rRNA gene PCR using 27F and 1492R primers followed by Sanger-based sequencing of the PCR product [75].

\section{Supplementary Information}

The online version contains supplementary material available at https://doi. org/10.1186/s13068-021-01958-2.

\footnotetext{
Additional file 1: Figure S1. Confirming the phenotypes of Drainas group strains CU1, CU1rif2 and uvs51. A. Glucose sensitivity was measured by growing strains ATCC10988 and its derivatives CU1, CU1 rif2 and uvs51 statically in aerobic conditions at $300 \mathrm{C}$ in ZRMG ( $2 \%$ glucose) or ZRMG supplemented with $10 \%$ glucose for 32 or 48 hours, respectively. B. Rifampicin resistance of strains CU1 rif2 and uvs 51 was confirmed by growing respective strains aerobically at $300 \mathrm{C}$ on ZRMG plates without and with $10 \mu \mathrm{g} / \mathrm{ml}$ of rifampicin. Figure $\mathbf{S 2} .5 \mathrm{ml}$ of ZRMG were inoculated from single colonies of each strain and grown overnight in anaerobic chamber to stationary phase. Cultures were diluted to OD600 0.1 in fresh anaerobic ZRMG. Isobutanol (IBA) was added to diluted cultures to final concentrations of $0.0,0.5$ and $1.0 \%$, mixed and aliquots of $150 \mu \mathrm{l}$ were loaded in triplicate onto 96 -well plate. Incubation was performed with shaking at $30^{\circ} \mathrm{C}$ until growth reached saturation (18 hours). Only the first 10 hours of the growth is shown because IC50 for ZM4 and percent of inhibition for all the strains were calculated from area under the curve after 8 hours of growth. Figure S3. Repeated growth of strains ZM4 and $\mathrm{Z} 6$ with isobutanol. Normalized OD600 after 9 hours of growth is shown
}

for cultures grown with $0 \%, 0.5 \%$, or $1 \% \mathrm{v} / \mathrm{v}$ isobutanol. Figure $\mathbf{S 4}$. Initial OD600 of cultures used for flocculation experiment described in Figure 7. Identical volume of the same colony resuspended in ZMMG was used to inoculate $5 \mathrm{ml}$ of ZMMG or ZRMG. Cultures were grown for 48 hours statically in $14 \mathrm{ml}$ plastic tubes in aerobic environment or in anaerobic chamber, or with shaking at $275 \mathrm{rpm}$ in Hungate tubes closed or loosely covered with aluminum foil for anaerobic and aerobic growth, respectively. Figure S5. The promoter region of the cellulose synthase (bcs) operon. A. Z. mobilis ZM4 promoter consensus sequence. Reproduced exactly as shown in: (Vera et al., 2020). B. Regulatory elements of the bcs operon: TSS -23 and -26 , and -10 and -35 elements are highlighted in yellow, the ZMO1080 start codon is highlighted in green. C. Clustal $\Omega$ alignment of the region upstream of the ZMO1080 start codon of $16 \mathrm{Z}$. mobilis mobilis strains. Pomaceae and francensis are not included for clarity. ZM4 regulatory elements are colored as in B and nucleotides different from consensus are highlighted in blue. A single nucleotide deletion is highlighted in red. Table S1. Genome statistics for Zymomonas strains sequenced for this study. (see separate Excel file). Table S2. Information on Zymomonas strains and genomes. A list of all strains that were used for physiological and/or genomic comparisons. Common names and reference numbers for the American Type Culture Collection (ATCC), USDA Agricultural Research Service Culture Collection (NRRL), and the German Collection of Microorganisms and Cell Cultures (DSMZ), and the original source of isolation are provided. Strains were grouped based on genome similarity (see text). Highlights indicate the strain designation used to refer to each strain throughout the text, figures, and subsequent tables. Table S3. Names, accession numbers and topology determination of plasmids analyzed in Table 2. (see separate Excel file). Table S4. Loci and predicted functions for 41 genes present in ATCC10988 but without detectable homologs in any of the 3 derivative strains in the Drainas group. Table S5. Full list of methylated sequences found in 9 de-novo sequenced Zymomonas mobilis genomes.

Additional file 2: Figure S6.Z. mobilis BcsA alignment (see figure in separate PDF). BCSA (ZMO1083) protein alignment was performed by Clustal $\Omega$ and visualized by ESPript 3.0 (Robert \& Gouet, 2014). Pomaceae and ZM4 are not included as they were not annotated or annotated as pseudogene, respectively. In CP4 bcsA G629A substitution results in a stop codon (TAG); Met 42 is a start codon and protein is truncated from $\mathrm{N}$-terminus. C-terminal truncation of PROIMIA1 BCsA is discussed in text. Residues with strict identity are in white on red. Threshold for high similarity was set at 0.7 and similar residues are shown in red and framed in blue. Weakly similar residues are shown in black.

Additional file 3: Figure S7. Z. mobilis BcsA alignment with secondary structures from Rhodobacter sphaeroides 4P02_A (see figure in separate PDF). BcsA (ZMO1083) was aligned with BcsA from R. sphaeroides using Clustal $\Omega$ and visualized by ESPript 3.0 (1). Secondary structures derived from R. sp. 3D structure (PDB 4P02) are shown at the top. $\alpha$ and $\pi$ helices are shown in medium and small squiggles, $\beta$ sheets as arrows and $\alpha$ or $\beta$ turns as TT or TTT, respectively. Color code is as in Figure S5. $\beta-16$ and $\beta-17$ of R. sphaeroids are part of a PilZ domain binding c-di GMP.

Additional file 4: Figure S8. Z. mobilis mobilis BcsC alignment (see figure in separate PDF). BCSC (ZMO1085) alignment was performed as described in Figure $S 5$ (BcsA). BcsC from pomaceae is a pseudogene and BcsC from francensis was omitted for clarity. BcsC of NCIMB11163 is fused in-frame with bcsZ. Only first residue of fused $\mathrm{Bcs} C Z$ protein is shown. All colors are as in Figure $\mathrm{S} 5$.

Additional file 5: Table S6. Merged orthologue and annotation data.

\section{Acknowledgements}

We thank Dr. Donna Bates for helpful comments on the manuscript and Dr. Robert Landick for providing the pRL814 plasmid.

\section{Authors' contributions}

MMF performed the experiments, analyzed data, prepared genomic DNA, and drafted and revised the manuscript. RMB performed bioinformatic analyses, drafted portions of the manuscript, and revised the manuscript. TW consulted on bioinformatic analyses and revised the manuscript. MAT designed the study, analyzed data, and drafted and revised the manuscript. 


\section{Funding}

This material is based upon work supported by the Great Lakes Bioenergy Research Center, U.S. Department of Energy, Office of Science, Office of Biological and Environmental Research under Award Number DE-SC0018409. The work conducted by the U.S. Department of Energy Joint Genome Institute, a DOE Office of Science User Facility, is supported under Contract No. DE-AC02-05CH11231.

\section{Availability of data and materials}

All raw and assembled genome sequences are publicly available under the accession numbers listed in Table 1. Methylation data can be found on JGI's Genome Portal pages (https://genome.jgi.doe.gov/portal/). Raw phenotypic data are available upon request to the authors.

\section{Declarations}

\section{Ethics approval and consent to participate}

No human or animal subjects were used in this research.

\section{Consent for publication}

All coauthors consent to submission and publication of this manuscript.

\section{Competing interests}

The authors declare no competing interests.

\section{Author details}

${ }^{1}$ Department of Biochemistry and Molecular Biology, Michigan State University, East Lansing, MI 48824, USA. ${ }^{2}$ U.S. Department of Energy Joint Genome Institute, Lawrence Berkeley National Laboratory, Berkeley, CA 94720, USA.

Received: 20 February 2021 Accepted: 17 April 2021

Published online: 01 May 2021

\section{References}

1. Yang S, Fei Q, Zhang Y, Contreras LM, Utturkar SM, Brown SD, Himmel ME, Zhang M. Zymomonas mobilis as a model system for production of biofuels and biochemicals. Microb Biotechnol. 2016;9:699-717.

2. Wohlbach DJ, Rovinskiy N, Lewis JA, Sardi M, Schackwitz WS, Martin JA, Deshpande S, Daum CG, Lipzen A, Sato TK, Gasch AP. Comparative genomics of Saccharomyces cerevisiae natural isolates for bioenergy production. Genome Biol Evol. 2014;6:2557-66.

3. Chen C, Wu L, Cao Q, Shao H, Li X, Zhang Y, Wang H, Tan X. Genome comparison of different Zymomonas mobilis strains provides insights on conservation of the evolution. PLoS ONE. 2018;13:e0195994.

4. De Ley J, Swings J. Phenotypic description, numerical analysis, and proposal for an improved taxonomy and nomenclature of the genus Zymomonas Kluyver and van Niel 1936. Int J Syst Evol Microbiol. 1976;26:146-57.

5. Yang S, Vera JM, Grass J, Savvakis G, Moskvin OV, Yang Y, Mcllwain SJ, Lyu Y, Zinonos I, Hebert AS, Coon JJ, Bates DM, Sato TK, Brown SD, Himmel ME, Zhang M, Landick R, Pappas KM, Zhang Y. Complete genome sequence and the expression pattern of plasmids of the model ethanologen Zymomonas mobilis ZM4 and its xylose-utilizing derivatives $8 \mathrm{~b}$ and 2032. Biotechnol Biofuels. 2018;11:125.

6. Chacon-Vargas K, Chirino AA, Davis MM, Debler SA, Haimer WR, Wilbur JJ, Mo X, Worthing BW, Wainblat EG, Zhao S, Gibbons JG. Genome Sequence of Zymomonas mobilis subsp. mobilis NRRL B-1960. Genome Announc. 2017;5:e00562-e617.

7. Kouvelis VN, Teshima H, Bruce D, Detter C, Tapia R, Han C, Tampakopoulou V-O, Goodwin L, Woyke T, Kyrpides NC, Typas MA, Pappas KM. Finished genome of Zymomonas mobilis subsp. mobilis strain CP4, an applied ethanol producer. Genome Announc. 2014;2:e00845-e913.

8. Desiniotis A, Kouvelis VN, Davenport K, Bruce D, Detter C, Tapia R, Han C, Goodwin LA, Woyke T, Kyrpides NC, Typas MA, Pappas KM. Complete genome sequence of the ethanol-producing Zymomonas mobilis subsp. mobilis centrotype ATCC 29191. J Bacteriol. 2012;194:5966-7.

9. Pappas KM, Kouvelis VN, Saunders E, Brettin TS, Bruce D, Detter C, Balakireva M, Han CS, Savvakis G, Kyrpides NC, Typas MA. Genome sequence of the ethanol-producing Zymomonas mobilis subsp. mobilis lectotype strain ATCC 10988. J Bacteriol. 2011;193:5051-2.

10. Kouvelis VN, Saunders E, Brettin TS, Bruce D, Detter C, Han C, Typas MA, Pappas KM. Complete genome sequence of the ethanol producer Zymomonas mobilis NCIMB 11163. J Bacteriol. 2009;191:7140-1.

11. Kouvelis VN, Davenport KW, Brettin TS, Bruce D, Detter C, Han CS, Nolan M, Tapia R, Damoulaki A, Kyrpides NC, Typas MA, Pappas KM. Genome sequence of the ethanol-producing Zymomonas mobilis subsp. pomaceae lectotype strain ATCC 29192. J Bacteriol. 2011;193:5049-50.

12. Delgado OD, Abate CM, Siñeriz F. Construction of an integrative shuttle vector for Zymomonas mobilis. FEMS Microbiol Lett. 1995;132:23-6.

13. Swings J, De Ley J. The biology of Zymomonas. Bacteriol Rev. 1977:41:1-46.

14. Weir PM. The ecology of Zymomonas: a review. Folia Microbiol (Praha). 2016;61(5):385-92.

15. Yu FB, Blainey PC, Schulz F, Woyke T, Horowitz MA, Quake SR. Microfluidicbased mini-metagenomics enables discovery of novel microbial lineages from complex environmental samples. Elife. 2017:6:e26580.

16. Leekitcharoenphon P, Kaas RS, Thomsen MCF, Friis C, Rasmussen S, Aarestrup FM. snpTree-a web-server to identify and construct SNP trees from whole genome sequence data. BMC Genomics. 2012;13:S6.

17. Tonkin-Hill G, Lees JA, Bentley SD, Frost SDW, Corander J. RhierBAPS: an $\mathrm{R}$ implementation of the population clustering algorithm hierBAPS. Wellcome Open Res. 2018;3:93.

18. Cheng L, Connor TR, Sirén J, Aanensen DM, Corander J. Hierarchical and spatially explicit clustering of DNA sequences with BAPS software. Mol Biol Evol. 2013;30:1224-8.

19. Gonçalves de Lima O, De Araujo JM, Schumacher IF, Da Silva EC. Estudos de microorganismos antagonistas presentes nas bebidas fermentadas usadas pelo povo do Recife. I. Sobre uma variedade de Zymomonas mobilis (Lindner)(1928). Rev Inst Antibiot Univ Recife. 1970;10:3-15.

20. Strandberg GW, Donaldson TL, Arcuri EJ. Continuous ethanol production by a flocculent strain of Zymomonas mobilis. Biotechnol Lett. 1982;4:347-52.

21. Dadds MJS, Martin PA, Carr JG. The doubtful status of the species Zymomonas anaerobia and Z. mobilis. J Appl Bacteriol. 1973;36:531-9.

22. Yablonsky MD, Goodman AE, Stevnsborg N, Gonçalves de Lima O, Falcão de Morais JO, Lawford HG, Rogers PL, Eveleigh DE. Zymomonas mobilis CP4: a clarification of strains via plasmid profiles. J Biotechnol. 1988;9:71-9.

23. Swings J, De Ley J. Genome deoxyribonucleic acid of the genus Zymomonas Kluyver and van Niel 1936: base composition, size, and similarities. Int J Syst Evol Microbiol. 1975:25:324-8.

24. Drainas C, Typas MA, Kinghorn JR. A derivative of Zymomonas mobilis ATCC 10988 with impared ethanol production. Biotechnol Lett. 1984;6:37-42

25. Afendra AS, Drainas C. Expression and stability of a recombinant plasmid in Zymomonas mobilis and Escherichia coli. Microbiology. 1987;133:127-34.

26. Vartholomatos G, Typas MA, Drainas C. An ultraviolet-sensitive mutant of Zymomonas mobilis affecting the stability of its natural plasmid pZMO2. Plasmid. 1993;29:10-8.

27. Coton M, Laplace J-M, Auffray Y, Coton E. Polyphasic study of Zymomonas mobilis strains revealing the existence of a novel subspecies $Z$. mobilis subsp. francensis subsp. nov., isolated from French cider. Int J Syst Evol Microbiol. 2006;56:121-5.

28. Sprouffske K, Wagner A. Growthcurver: an R package for obtaining interpretable metrics from microbial growth curves. BMC Bioinformatics. 2016;17:172.

29. Weber C, Farwick A, Benisch F, Brat D, Dietz H, Subtil T, Boles E. Trends and challenges in the microbial production of lignocellulosic bioalcohol fuels. Appl Microbiol Biotechnol. 2010;87:1303-15.

30. Skerker JM, Leon D, Price MN, Mar JS, Tarjan DR, Wetmore KM, Deutschbauer AM, Baumohl JK, Bauer S, Ibáñez AB, Mitchell VD, Wu CH, Hu P, Hazen T, Arkin AP. Dissecting a complex chemical stress: chemogenomic profiling of plant hydrolysates. Mol Syst Biol. 2013;9:674.

31. He M, Wu B, Shui Z, Hu Q, Wang W, Tan F, Tang X, Zhu Q, Pan K, Li Q, Su X. Transcriptome profiling of Zymomonas mobilis under furfural stress. Appl Microbiol Biotechnol. 2012;95:189-99.

32. Zaldivar J, Martinez A, Ingram LO. Effect of selected aldehydes on the growth and fermentation of ethanologenic Escherichia coli. Biotechnol Bioeng. 1999;65:24-33. 
33. Zhang M, Eddy C, Deanda K, Finkelstein M, Picataggio S. Metabolic engineering of a pentose metabolism pathway in ethanologenic Zymomonas mobilis. Science. 1995;267:240-3.

34. Dunn KL, Rao CV. Expression of a xylose-specific transporter improves ethanol production by metabolically engineered Zymomonas mobilis. Appl Microbiol Biotechnol. 2014;98:6897-905.

35. Dk L, V. RC. . High-throughput sequencing reveals adaptation-induced mutations in pentose-fermenting strains of Zymomonas mobilis. Biotechnol Bioeng. 2015;112:2228-40.

36. Jeon J-M, Park H, Seo H-M, Kim J-H, Bhatia SK, Sathiyanarayanan G, Song H-S, Park S-H, Choi K-Y, Sang B-I, Yang Y-H. Isobutanol production from an engineered Shewanella oneidensis MR-1. Bioprocess Biosyst Eng. 2015;38(11):2147-54

37. Qiu M, Shen W, Yan X, He Q, Cai D, Chen S, Wei H, Knoshaug EP, Zhang M, Himmel ME, Yang S. Metabolic engineering of Zymomonas mobilis for anaerobic isobutanol production. Biotechnol Biofuels. 2020;13:15.

38. Wess J, Brinek M, Boles E. Improving isobutanol production with the yeast Saccharomyces cerevisiae by successively blocking competing metabolic pathways as well as ethanol and glycerol formation. Biotechnol Biofuels. 2019;12:173.

39. Roberts RJ, Vincze T, Posfai J, Macelis D. REBASE-a database for DNA restriction and modification: enzymes, genes and genomes. Nucleic Acids Res. 2015;43:D298-9.

40. Gonzalez D, Kozdon JB, MCAdams HH, Shapiro L, Collier J. The functions of DNA methylation by CcrM in Caulobacter crescentus: a global approach. Nucleic Acids Res. 2014:42:3720-35.

41. Brenac L, Baidoo EEK, Keasling JD, Budin I. Distinct functional roles for hopanoid composition in the chemical tolerance of Zymomonas mobilis. Mol Microbiol. 2019;112:1564-75.

42. Flusberg BA, Webster DR, Lee JH, Travers KJ, Olivares EC, ClarkTA, Korlach J, Turner SW. Direct detection of DNA methylation during single-molecule, real-time sequencing. Nat Methods. 2010;7:461-5.

43. Kerr AL, Jeon YJ, Svenson CJ, Rogers PL, Neilan BA. DNA restrictionmodification systems in the ethanologen, Zymomonas mobilis ZM4. Appl Microbiol Biotechnol. 2011;89(3):761-9.

44. Wu B, He MX, Luo AJ, Zhang Y, Feng H, Hu QC, Zhang YZ. Construction and characterization of restriction-modification deficient mutants in Zymomonas mobilis ZM4. Chin J Appl Env Biol. 2013;19:189-97.

45. Zheng Y, Han J, Wang B, Hu X, Li R, Shen W, Ma X, Ma L, Yi L, Yang S, Peng W. Characterization and repurposing of the endogenous Type I-F CRISPRCas system of Zymomonas mobilis for genome engineering. Nucleic Acids Res. 2019;47:11461-75.

46. Ghosh IN, Martien J, Hebert AS, Zhang Y, Coon JJ, Amador-Noguez D, Landick R. OptSSeq explores enzyme expression and function landscapes to maximize isobutanol production rate. Metab Eng. 2019;52:324-40.

47. Felczak MM, Jacobson TB, Ong WK, Amador-Noguez D, TerAvest MA. Expression of phosphofructokinase is not sufficient to enable embdenmeyerhof-parnas glycolysis in Zymomonas mobilis ZM4. Front Microbiol. 2019. https://doi.org/10.3389/fmicb.2019.02270.

48. Lee JH, Skotnicki ML, Rogers PL. Kinetic studies on a flocculent strain of Zymomonas mobilis. Biotechnol Lett. 1982;4:615-20.

49. Lal PB, Wells FM, Lyu Y, Ghosh IN, Landick R, Kiley PJ. A markerless method for genome engineering in Zymomonas mobilis ZM4. Front Microbiol. 2019. https://doi.org/10.3389/fmicb.2019.02216.

50. Xia J, Liu C-G, Zhao X-Q, Xiao Y, Xia X-X, Bai F-W. Contribution of cellulose synthesis, formation of fibrils and their entanglement to the self-flocculation of Zymomonas mobilis. Biotechnol Bioeng. 2018;115:2714-25.

51. Fein JE, Zawadzki BC, Lawford HG, Lawford GR. Controlling morphological instability of Zymomonas mobilis strains in continuous culture. Appl Environ Microbiol. 1983:45:1899 LP - 1904.

52. Palha MAPF, Lopes CE, Pereira N. Ethanol stimulates the flocculation of Zymomonas mobilis. Biotechnol Lett. 1997;19:499-501.

53. Jones-Burrage SE, Kremer TA, McKinlay JB. Cell aggregation and aerobic respiration are important for Zymomonas mobilis ZM4 survival in an aerobic minimal medium. Appl Environ Microbiol. 2019:85:e00193-e219.

54. Vera JM, Ghosh IN, Zhang Y, Hebert AS, Coon JJ, Landick R. Genome-scale transcription-translation mapping reveals features of Zymomonas mobilis transcription units and promoters. mSystems. 2020;5:e00250-e320.

55. Morgan JLW, Strumillo J, Zimmer J. Crystallographic snapshot of cellulose synthesis and membrane translocation. Nature. 2013;493:181-6.
56. Jeon YJ, Xun Z, Su P, Rogers PL. Genome-wide transcriptomic analysis of a flocculent strain of Zymomonas mobilis. Appl Microbiol Biotechnol. 2012:93:2513-8.

57. Rehman ZU, Rehm BHA. Dual roles of Pseudomonas aeruginosa AlgE in secretion of the virulence factor alginate and formation of the secretion complex. Appl Environ Microbiol. 2013;79:2002-11.

58. Römling U, Galperin MY. Bacterial cellulose biosynthesis: diversity of operons, subunits, products, and functions. Trends Microbiol. 2015;23:545-57.

59. Eid J, Fehr A, Gray J, Luong K, Lyle J, Otto G, Peluso P, Rank D, Baybayan P, Bettman B, Bibillo A, Bjornson K, Chaudhuri B, Christians F, Cicero R, Clark S, Dalal R, Dewinter A, Dixon J, Foquet M, Gaertner A, Hardenbol P, Heiner C, Hester K, Holden D, Kearns G, Kong X, Kuse R, Lacroix Y, Lin S, Lundquist P, Ma C, Marks P, Maxham M, Murphy D, Park I, Pham T, Phillips M, Roy J, Sebra R, Shen G, Sorenson J, Tomaney A, Travers K, Trulson M, Vieceli J, Wegener J, Wu D, Yang A, Zaccarin D, Zhao P, Zhong F, Korlach J, Turner S. Real-time DNA sequencing from single polymerase molecules. Science. 2009;323:133-8.

60. Chin C-S, Alexander DH, Marks P, Klammer AA, Drake J, Heiner C, Clum A, Copeland A, Huddleston J, Eichler EE, Turner SW, Korlach J. Nonhybrid, finished microbial genome assemblies from long-read SMRT sequencing data. Nat Methods. 2013;10:563-9.

61. Chaisson MJ, Tesler G. Mapping single molecule sequencing reads using basic local alignment with successive refinement (BLASR): application and theory. BMC Bioinformatics. 2012;13:238.

62. Clark TA, Murray IA, Morgan RD, Kislyuk AO, Spittle KE, Boitano M, Fomenkov A, Roberts RJ, Korlach J. Characterization of DNA methyltransferase specificities using single-molecule, real-time DNA sequencing. Nucleic Acids Res. 2012;40:e29.

63. Katoh K, Standley DM. MAFFT multiple sequence alignment software version 7: improvements in performance and usability. Mol Biol Evol. 2013;30:772.

64. Capella-Gutiérrez S, Silla-Martínez JM, Gabaldón T. trimAl: a tool for automated alignment trimming in large-scale phylogenetic analyses. Bioinformatics. 2009;25:1972.

65. Nguyen L-T, Schmidt HA, von Haeseler A, Minh BQ. IQ-TREE: a fast and effective stochastic algorithm for estimating maximum-likelihood phylogenies. Mol Biol Evol. 2015;32:268-74.

66. Yu G, Smith DK, Zhu H, Guan Y, Lam TT-Y. ggtree: an r package for visualization and annotation of phylogenetic trees with their covariates and other associated data. Methods Ecol Evol. 2017:8:28-36.

67. Kurtz S, Phillippy A, Delcher AL, Smoot M, Shumway M, Antonescu C, Salzberg SL. Versatile and open software for comparing large genomes. Genome Biol. 2004;5:R12.

68. Jain C, Rodriguez-R LM, Phillippy AM, Konstantinidis KT, Aluru S. High throughput ANI analysis of $90 \mathrm{~K}$ prokaryotic genomes reveals clear species boundaries. Nat Commun. 2018:9:5114.

69. Enright AJ, Van Dongen S, Ouzounis CA. An efficient algorithm for largescale detection of protein families. Nucleic Acids Res. 2002;30:1575-84.

70. Chen I-MA, Chu K, Palaniappan K, Pillay M, Ratner A, Huang J, Huntemann $M$, Varghese N, White JR, Seshadri R, Smirnova T, Kirton E, Jungbluth SP, Woyke T, Eloe-Fadrosh EA, Ivanova NN, Kyrpides NC. IMG/M vol 5.0: an integrated data management and comparative analysis system for microbial genomes and microbiomes. Nucleic Acids Res. 2019;47:D666-77.

71. Emms DM, Kelly S. OrthoFinder: solving fundamental biases in whole genome comparisons dramatically improves orthogroup inference accuracy. Genome Biol. 2015;16:157.

72. Blodgett JAV, Thomas PM, Li G, Velasquez JE, van der Donk WA, Kelleher $\mathrm{NL}$, MetcalfWW. Unusual transformations in the biosynthesis of the antibiotic phosphinothricin tripeptide. Nat Chem Biol. 2007:3:480-5.

73. Neumann B, Pospiech A, Schairer HU. Rapid isolation of genomic DNA from Gram-negative bacteria. Trends Genet. 1992;8:332-3.

74. Sambrook J, Fritsch EF, Maniatis T. Molecular cloning: a laboratory manual. New York: Cold Spring Harbor Laboratory Press; 1989.

75. Lane D. 16S/23S rRNA Sequencing. In: Stackebrandt E, Goodfellow M, editors. Nucleic acid techniques in bacterial systematics. New York: Wiley; 1991. p. 115-76.

\section{Publisher's Note}

Springer Nature remains neutral with regard to jurisdictional claims in published maps and institutional affiliations. 